\title{
Design of Micropillar Wicks for Thin-Film
}

\section{Evaporation}

\author{
Solomon Adera ${ }^{1}$, Dion Antao ${ }^{1}$, Rishi Raj ${ }^{1,2}$, and Evelyn N. Wang ${ }^{1, *}$ \\ ${ }^{1}$ Device Research Laboratory, Department of Mechanical Engineering, Massachusetts Institute of Technology, \\ 77 Massachusetts Avenue, Cambridge, Massachusetts 02139, USA \\ ${ }^{2}$ Thermal and Fluid Transport Laboratory, Department of Mechanical Engineering, Indian Institute of Technology \\ Patna, Bihar 801103, India \\ *Address correspondence to enwang@mit.edu
}

\begin{abstract}
The generation of concentrated heat loads in advanced microprocessors, GaN electronics, and solar cells present significant thermal management challenges in defense, space and commercial applications. Liquid to vapor phase-change strategies are promising due to the high latent heat of vaporization of the working fluid. In particular, thin-film evaporation has received increased interest owing to advances in micro/nanofabrication and the potential to dissipate high heat fluxes by increasing the evaporative meniscus area. Yet, predictive tools to design various wicking structures are limited due to the complexity of the thermal-fluidic transport. In this work, we performed systematic experiments to characterize capillary-limited thin-film evaporation from silicon micropillar wicks in the absence of nucleate boiling. The insights gained from experiments were used to model the capillary pressure, permeability, and thermal resistance. Accordingly, we developed a semi-analytical model to determine the capillary-limited dryout heat flux and wall temperature with $\pm 20 \%$ accuracy, compared to our experiments. The model provides a versatile platform to design and optimize micropillar wicks for next generation thermal management devices.
\end{abstract}

Keywords: thermal performance, thin-film evaporation, capillary wicking, capillary limit, micropillar wick, optimization, dryout heat flux, heat pipe, vapor chamber 


\section{Nomenclature}

\begin{tabular}{|c|c|c|c|}
\hline$A$ & Area $\left(m^{2}\right)$ & $\Lambda$ & Correction factor/height ratio (- \\
\hline$D$ & Diameter (m) & $\theta$ & Contact angle $\left({ }^{\circ}\right)$ \\
\hline$g$ & Acceleration due to gravity $\left(\mathrm{m} / \mathrm{s}^{2}\right)$ & $\lambda$ & Eigen value $\left(\mathrm{m}^{-1}\right)$ \\
\hline$H$ & Height (m) & $\mu$ & Dynamic viscosity $(\mathrm{kg} / \mathrm{m} \cdot \mathrm{s})$ \\
\hline HO & Heater (-) & $v$ & Specific volume $\left(\mathrm{m}^{3} / \mathrm{kg}\right)$ \\
\hline$h$ & Enthalpy (J/kg) & $\xi$ & Geometric parameter $(\mathrm{m})$ \\
\hline$I, i$ & Current (A) & $\rho$ & Density $\left(\mathrm{kg} / \mathrm{m}^{3}\right)$ \\
\hline$j$ & Counter, $j=1,2,3, \ldots(-)$ & $\sigma$ & Surface tension $(\mathrm{N} / \mathrm{m})$ \\
\hline$K$ & Permeability $\left(m^{2}\right)$ & $\phi_{s}$ & Solid fraction (-) \\
\hline$k$ & Thermal conductivity $(\mathrm{W} / \mathrm{m} \cdot \mathrm{K})$ & $\chi$ & Accommodation coefficient (-) \\
\hline$L$ & Spacing $(m)$ & $\psi$ & Geometric parameter (-) \\
\hline$l$ & Dryout length $(\mathrm{m})$ & $\omega$ & Wave length (m) \\
\hline$M$ & Figure of merit $\left(\mathrm{W} / \mathrm{m}^{2}\right)$ & \multicolumn{2}{|c|}{ Subscripts } \\
\hline $\bar{M}$ & Molecular mass (kg/mol) & Bo & Bond number (-) \\
\hline$N$ & Number of pillars (-) & cap & Capillary \\
\hline
\end{tabular}




\begin{tabular}{|c|c|c|c|}
\hline$n$ & Index of refraction (-) & con & Constriction \\
\hline$P$ & Pressure (Pa) & eff & Effective \\
\hline$q^{\prime \prime}$ & Heat flux $\left(\mathrm{W} / \mathrm{m}^{2}\right)$ & $e q$ & Equivalent \\
\hline $\mathrm{S}$ & Sensors 1, 2, and $3(-)$ & $f g$ & Liquid-to-vapor \\
\hline$R$ & Thermal resistance $(\mathrm{K} / \mathrm{W})$ & int & Interfacial \\
\hline $\bar{R}$ & Universal gas constant $(\mathrm{J} / \mathrm{mol} \cdot \mathrm{K})$ & $l$ & liquid \\
\hline$r$ & Electrical resistance $(\Omega)$ & $L V$ & Liquid-vapor interface \\
\hline$T$ & Temperature (K) & $p$ & Pillar \\
\hline$t$ & Thickness (m) & $P S$ & Power source \\
\hline$u$ & Velocity $(\mathrm{m} / \mathrm{s})$ & rec & Receding \\
\hline $\bar{u}$ & Average velocity $(\mathrm{m} / \mathrm{s})$ & sat & Saturation \\
\hline$V$ & Voltage (V) & Si & Silicon \\
\hline$x, y, z$ & Cartesian coordinate & $s p$ & Spreading \\
\hline Greek & Symbols & sub & Substrate \\
\hline$\beta$ & Geometric parameter $\left(\mathrm{m}^{-1}\right)$ & $T F$ & Thin-film \\
\hline$\Delta$ & Difference & $v$ & Vapor \\
\hline
\end{tabular}




$$
\varepsilon \quad \text { Porosity (-) w Water }
$$

\section{Introduction and background}

Thermal management is increasingly becoming a bottleneck for a variety of high performance devices such as integrated circuits, microprocessors, and GaN based power amplifiers where the heat generation at the device footprint has surpassed $100 \mathrm{~W} / \mathrm{cm}^{2}$ $[1,2]$. Such concentrated heat loads are challenging to remove using traditional single-phase convective air and liquid cooling due to the low thermal capacity of air and the need for a large pumping power, respectively $[1,3,4]$. Furthermore, the improvements that can be achieved via direct extensions of single-phase convective cooling solutions have limitations. For example, increased fan speed for air cooling increases the noise emission and energy consumption in addition to reducing reliability [5]. Similarly, an increased flow rate for single-phase convective liquid cooling decreases the coefficient of performance (COP) in addition to increasing the size and weight of the device [1]. Consequently, phase-change-based thermal management solutions which utilize the large latent heat of vaporization as the working fluid changes phase from liquid to vapor are required for many applications $[3,4,6]$. Furthermore, phase-change-based cooling strategies reduce size, weight, and power consumption making them suitable for small-scale devices such as microelectronic chips.

One phase-change based cooling strategy that has received significant interest is thin-film evaporation $[7,8]$, which has been used in heat pipes $[9,10]$ and can be used in other closed-loop configurations for high heat flux thermal management [6]. Thin-film 
evaporation relies on the phase-change of a thin liquid film ( $\approx$ few microns) from the liquid-vapor interface of an extended meniscus near the three phase contact line [11]. The extended meniscus improves the thermal transport and the rate of heat dissipation near the thin-film region by increasing the evaporation area and decreasing the conduction resistance $[8,12]$. The area of the extended meniscus and the thin-film region can be increased to maximize the rate of heat dissipation by varying the surface area-to-volume ratio via micro/nano-structuring [11, 13]. More importantly, these micro/nano-structured surfaces can offer the advantage of passive liquid transport via capillary wicking, such as in heat pipes $[9,10]$. Accordingly, liquid dryout in these wicks occurs when viscous losses exceed the capillary pressure, i.e., the capillary limit. Furthermore, the thermal performance of thin-film evaporation is determined by the wick design.

Prior thin-film evaporation studies have shown that the desired characteristics of wicks for efficient fluidic and thermal transport are small characteristic length scale, high porosity, high permeability, high capillarity, and large extended menisci [14, 15]. However, a quantitative relationship between the various parameters is still missing, which limits the ability to optimize these wicks for maximum thermal-fluidic performance.

In past experimental studies of micro/nano-structured wicks, thin-film evaporation has often been coupled with nucleate boiling even at relatively low superheats (Table 1). In addition, the transition from thin-film evaporation to nucleate boiling in these studies could not be clearly delineated $[11,16]$. For example, due to the difficulty of experimentally locating the transition point from thin-film evaporation to 
International Journal of Heat and Mass Transfer

nucleate boiling, Ćoso, et al. [11] identified two overlapping regimes, i.e., regime where evaporation dominates over boiling and vice versa. More importantly, separating the two modes of heat transfer or locating the transition from thin-film evaporation to nucleate boiling is necessary since the onset of nucleate boiling (ONB) is another distinct failure mode, i.e., the boiling limit $[9,10]$. 
Table 1. Summary of representative experimental studies of the mixed boiling mode with evaporation and boiling. The working fluid in all of the experiments is water.

\begin{tabular}{|c|c|c|c|c|c|}
\hline Authors & Wick structure & $\begin{array}{l}\text { Superheat } \\
\text { at ONB }\end{array}$ & $\begin{array}{l}\text { Heat flux at } \\
\text { ONB }\end{array}$ & $\begin{array}{l}\text { Mode of heat } \\
\text { transfer }\end{array}$ & Remark \\
\hline $\begin{array}{l}\text { M. Hanlon } \\
\text { and H. Ma } \\
{[16]}\end{array}$ & $\begin{array}{l}\text { Monoporous sintered copper } \\
\text { wicks, } \\
\text { particle radius } 635 \mu \mathrm{m}, \\
\text { wick thickness } 1.9-5.7 \mathrm{~mm} \text {, } \\
\text { porosity } 0.43\end{array}$ & $\approx 5^{\circ} \mathrm{C}$ & $5-20 \mathrm{~W} / \mathrm{cm}^{2}$ & $\begin{array}{l}\text { Thin-film } \\
\text { evaporation/ } \\
\text { nucleate } \\
\text { boiling }\end{array}$ & $\begin{array}{l}1 \text { atm, } \\
\text { boiling before dryout }\end{array}$ \\
\hline $\begin{array}{l}\text { C. Li and G. } \\
\text { Peterson } \\
{[17]}\end{array}$ & $\begin{array}{l}\text { Sintered isotropic copper screen } \\
\text { mesh, } \\
\text { wire diameter } 56-191 \mu \mathrm{m}, \\
\text { wick thickness } 0.74 \mathrm{~mm} \text {, } \\
\text { porosity } 0.409-0.692\end{array}$ & - & - & $\begin{array}{l}\text { Evaporation/ } \\
\text { boiling }\end{array}$ & $\begin{array}{l}\text { Transition from } \\
\text { evaporation to nucleate } \\
\text { boiling difficult to } \\
\text { identify, } \\
\text { boiling before dryout }\end{array}$ \\
\hline $\begin{array}{l}\text { C. Li, et al. } \\
{[18]}\end{array}$ & $\begin{array}{l}\text { Sintered isotropic copper mesh, } \\
\text { wire diameter } 56 \mu \mathrm{m}, \\
\text { porosity } 0.693-0.737, \\
\text { wick thickness } 0.21-0.82 \mathrm{~mm}\end{array}$ & - & - & $\begin{array}{l}\text { Evaporation/ } \\
\text { boiling }\end{array}$ & $\begin{array}{l}\text { Transition from } \\
\text { evaporation to nucleate } \\
\text { boiling was difficult to } \\
\text { identify, } \\
\text { boiling before dryout }\end{array}$ \\
\hline $\begin{array}{l}\text { T. Semenic, } \\
\text { et al. [19] }\end{array}$ & $\begin{array}{l}\text { Biporous sintered copper wicks, } \\
\text { particle diameter } 29-63 \mu \mathrm{m}, \\
\text { average cluster diameter } \\
250-710 \mu \mathrm{m}, \\
\text { wick thickness } 1-4 \mathrm{~mm}, \\
\text { porosity } 0.597-0.631\end{array}$ & $\approx 4-5^{\circ} \mathrm{C}$ & $\approx 17-22 \mathrm{~W} / \mathrm{cm}^{2}$ & $\begin{array}{l}\text { Evaporation/ } \\
\text { nucleate } \\
\text { boiling }\end{array}$ & $\begin{array}{l}0.1 \text { atm, } \\
\text { boiling before dryout }\end{array}$ \\
\hline
\end{tabular}




\begin{tabular}{|c|c|c|c|c|c|}
\hline $\begin{array}{l}\text { D. Ćoso, et } \\
\text { al. [11] }\end{array}$ & $\begin{array}{l}\text { Silicon micropillars wicks, } \\
\text { pillar diameter 3-29 } \mu \mathrm{m}, \\
\text { microchannel width } 30-60 \mu \mathrm{m}, \\
\text { pin fin diameter 3.1-29 } \mu \mathrm{m}, \\
\text { spacing 8-57 } \mu \mathrm{m}, \\
\text { wick depth } 56-243 \mu \mathrm{m}, \\
\text { porosity } \approx 0.8\end{array}$ & $\approx 10^{\circ} \mathrm{C}$ & $\approx 60 \mathrm{~W} / \mathrm{cm}^{2}$ & $\begin{array}{l}\text { Evaporation/ } \\
\text { boiling }\end{array}$ & $\begin{array}{l}1 \text { atm, } \\
\text { boiling before dryout }\end{array}$ \\
\hline $\begin{array}{l}\text { Q. Cai and A. } \\
\text { Bhunia [20] }\end{array}$ & $\begin{array}{l}\text { Silicon micropillar wicks, } \\
\text { pillar diameter/pores } \\
10-100 \mu \mathrm{m}, \\
\text { pillar spacing } 30-100 \mu \mathrm{m}, \\
\text { micropore spacing } 50 \mu \mathrm{m}, \\
\text { pillar height } 320 \mu \mathrm{m}\end{array}$ & $\approx 6^{\circ} \mathrm{C}$ & $\approx 22.5 \mathrm{~W} / \mathrm{cm}^{2}$ & $\begin{array}{l}\text { Evaporation/ } \\
\text { boiling }\end{array}$ & $\begin{array}{l}1 \text { atm, } \\
\text { boiling before dryout }\end{array}$ \\
\hline $\begin{array}{l}\text { Q. Cai and } \\
\text { C.-L. Chen } \\
{[21]}\end{array}$ & $\begin{array}{l}\text { CNT biwick structures, } \\
\text { diameter <20 nm, } \\
\text { cluster spacing } 50 \mu \mathrm{m}, \\
\text { cluster width } 100 \mu \mathrm{m}, \\
\text { wick thickness } 250 \mu \mathrm{m}, \\
\text { porosity }>0.95\end{array}$ & $<5^{\circ} \mathrm{C}$ & $\approx 50 \mathrm{~W} / \mathrm{cm}^{2}$ & $\begin{array}{l}\text { Evaporation/ } \\
\text { boiling }\end{array}$ & $\begin{array}{l}\text { Saturated environment, } \\
\text { different temperatures, } \\
\text { boiling before dryout }\end{array}$ \\
\hline $\begin{array}{l}\text { J. A. Weibel, } \\
\text { et al. [22] }\end{array}$ & $\begin{array}{l}\text { Sintered copper powder wicks, } \\
\text { particle diameter } 45-355 \mu \mathrm{m}, \\
\text { wick thickness } 600-1200 \mu \mathrm{m}, \\
\text { porosity } \approx 0.65\end{array}$ & $\approx 5.5^{\circ} \mathrm{C}$ & $\approx 70 \mathrm{~W} / \mathrm{cm}^{2}$ & $\begin{array}{l}\text { Evaporation } \\
\text { then boiling }\end{array}$ & $\begin{array}{l}1 \text { atm, } \\
\text { transition from } \\
\text { evaporation to boiling } \\
\text { identified, } \\
\text { boiling before dryout }\end{array}$ \\
\hline $\begin{array}{l}\text { Q. Cai and A. } \\
\text { Bhunia [13] }\end{array}$ & $\begin{array}{l}\text { CNT bi-porous wick structures, } \\
\text { effective pore size } \approx 50-180 \mathrm{~nm} \text {, } \\
\text { heater area } 2 \times 2 \mathrm{~mm}^{2}, \\
\text { porosity } \approx 0.95\end{array}$ & $\lesssim 5^{\circ} \mathrm{C}$ & $\begin{array}{l}\approx 45-50 \mathrm{~W} / \mathrm{cm}^{2} \\
\text { (intermittent } \\
\text { nucleate } \\
\text { boiling) }\end{array}$ & $\begin{array}{l}\text { Evaporation } \\
\text { then boiling }\end{array}$ & $\begin{array}{l}\text { Clusters of CNT } \\
\text { separated by microscale } \\
\text { flow passages, } \\
\text { continuous nucleate } \\
\text { boiling } \approx 150 \mathrm{~W} / \mathrm{cm}^{2}\end{array}$ \\
\hline
\end{tabular}


The objectives of the present investigation are two-fold: (a) characterizing experimentally thin-film evaporation from well-defined micropillar wicks, and (b) developing a semi-analytical model for the optimization of wick designs for maximum thin-film evaporation performance. We fabricated silicon micropillars which enabled the ability to tailor the wick geometry for systematic experimental characterization and model development. We also designed our test devices and experiments to isolate thin-film evaporation from nucleate boiling. Based on the understanding gained from the experiments, we developed models for the permeability of the wick, the capillary pressure at the receding meniscus, and the thermal resistance. The sub-models were combined to create a comprehensive unified model for predicting the capillary-limited dryout heat flux in micropillar wicks.

We organized our paper as follows. We first discuss the design of the test device in Section 2, which is followed by experimental characterization and methodology in Section 3. Then, we discuss the experimental results in Section 4. In Section 5, we develop a thermal-fluidic model by conserving mass, momentum, and energy in the liquid domain, which is then validated with our experiments in Section 6. Finally, we summarize our findings in Section 7.

\section{Design and microfabrication of test device}

We describe the design of our test device and the microfabrication steps in this section. The overall dimension of the test device was $3 \times 3 \mathrm{~cm}^{2}$ with the center $1 \times 1 \mathrm{~cm}^{2}$ area microstructured for evaporation (Fig. 1a). The microstructured area was surrounded by a 
$6 \mathrm{~mm}$ wide primary water reservoir which has the same depth as the microstructured surface. The water reservoir was covered from the top and water was delivered to the reservoir via four $2.5 \mathrm{~mm}$ diameter inlet ports. The entire microstructured area was uniformly heated using a $1 \times 1 \mathrm{~cm}^{2}$ thin-film heater. Backside temperature was measured using thin-film sensors (Fig. 1b). Water was transported from the primary reservoir to the microstructured evaporative surface by capillary forces [23] acting at the three-phase contact line in the fluid-filled interstices of the micropillar wick, i.e., capillarity (Fig. 1c).

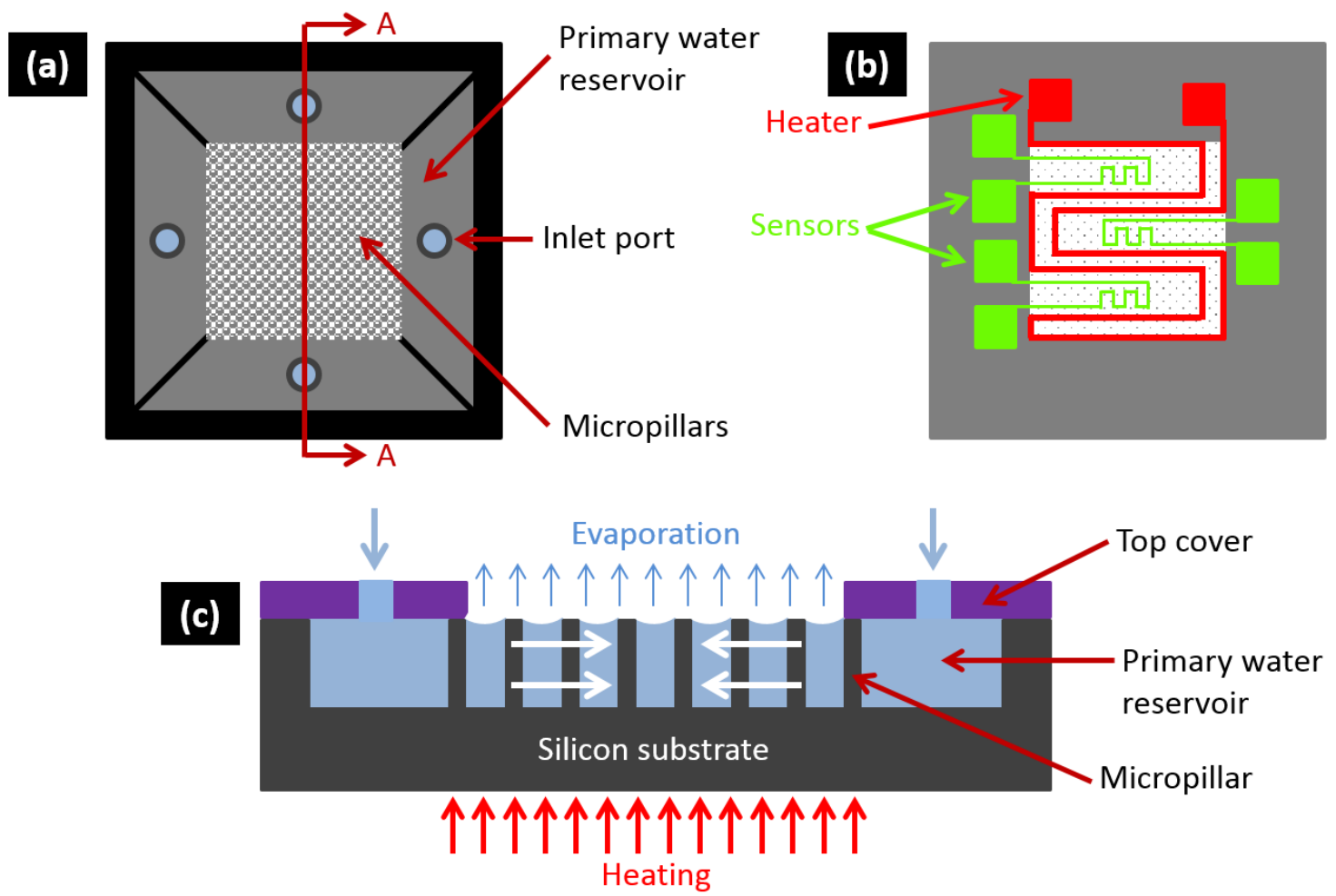

Fig. 1. Schematic (not-to-scale) design of the test device (a) front, (b) back, and (c) cross-section A-A. The cross-sectional view A-A shows the concept of capillarity, i.e., water is transported from the primary reservoir to the microstructured surface via 
capillary wicking. The sensors are embedded in between the lead wire traces of the heater.

We used standard silicon fabrication technology, including contact photolithography and deep-reactive-ion-etching (DRIE), to fabricate our test devices from a double-side polished 6" silicon wafers. The water reservoir at each edge of the microstructured surface was separated by a $70 \mu \mathrm{m}$ wide partition wall (Fig. 2a) to avoid intra-reservoir communication. The inlet ports on the top silicon cover (Fig. 2b) were created via time-multiplexed DRIE. The top silicon cover was bonded to the test device via direct fusion bonding (Fig. 2c). At the backside of each test device, we incorporated a $100 \mathrm{~nm}$ platinum thin-film heater (H0, Fig. 2d) and three sensors (S1, S2, and S3, Fig. 2d) via electron-beam evaporation and acetone lift-off. A $1 \mu \mathrm{m}$ thermally grown oxide layer was used for dielectric insulation. The thin-film heater provides uniform heating over $1 \times 1 \mathrm{~cm}^{2}$ area and the sensors measure the local temperature over a $640 \times 620 \mu \mathrm{m}^{2}$ footprint. The thin-film heaters and sensors were annealed at $350^{\circ} \mathrm{C}$ for $4 \mathrm{hrs}$ in a nitrogen environment. This was followed by calibration in a forced air convection oven using a high accuracy fluid immersion platinum resistance temperature detector (RTD-810, Omega Engineering) for measuring the oven temperature. The sensor resistance changed linearly with temperature with $<1 \%$ root-mean-square error (RMSE) and has $2.4 \Omega /{ }^{\circ} \mathrm{C}$ sensitivity. The $1 \times 1 \mathrm{~cm}^{2}$ microstructured area comprises of well-defined silicon micropillar arrays in a square pattern with pillar diameter $(D)$, height/micropillar wick thickness $(H)$, and center-to-center spacing ( $L$ ) (Fig. 2e). For systematic characterization, $D, H$, and $L$ were varied between 5-12, 30-90, and 12-20 $\mu \mathrm{m}$, respectively (Table 2). 
Table 2. List of test devices used in this study with micropillar array dimensions in $\mu \mathrm{m}$ (measurement uncertainty for $D$ and $H$ is $\pm 1 \mu \mathrm{m}$ ).

\begin{tabular}{cccc}
\hline Device ID & $D$ & $H$ & $L$ \\
\hline 1 & 5 & 82 & 12 \\
2 & 12 & 35 & 20 \\
3 & 12 & 76 & 20 \\
4 & 12 & 80 & 20 \\
5 & 12 & 90 & 20 \\
6 & 8 & 80 & 12 \\
7 & 8 & 82 & 16 \\
8 & 8 & 77 & 20 \\
9 & 5 & 74 & 20 \\
\hline
\end{tabular}
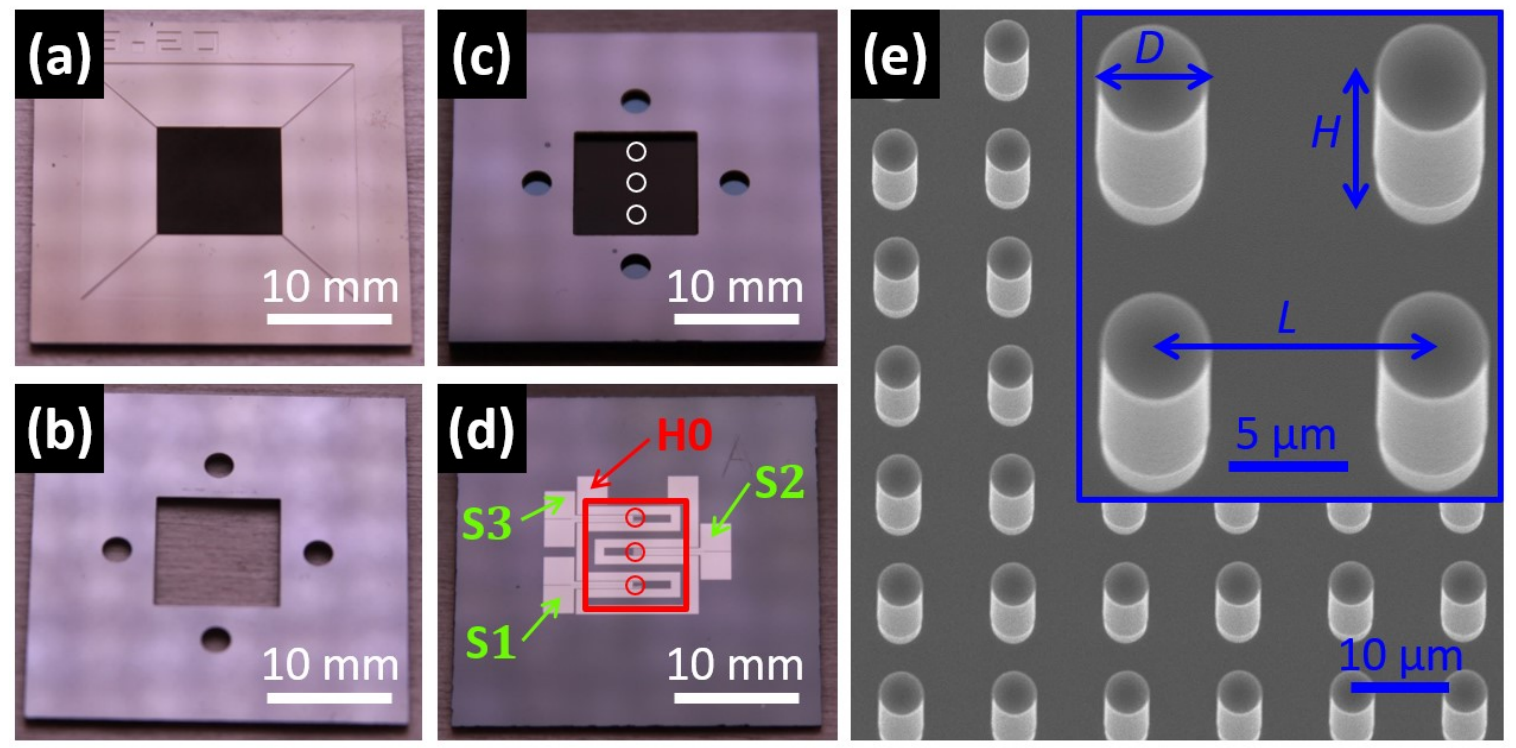

Fig. 2. (a) Front side of the test device showing the primary water reservoir and partition walls. (b) Top silicon cover with four inlet ports. (c) Front side of the test device after bonding the device in (a) and the top cover in (b) via direct fusion bonding. The three white circles in the microstructured surface show the relative location of the temperature sensors with respect to the microstructured area. (d) Backside of the test device showing the thin-film heater (HO) and sensors (S1, S2, and S3 for sensors 1, 2, and 3, respectively). 
The heater (red square box), which coincides with the microstructured area $\left(1 \times 1 \mathrm{~cm}^{2}\right)$, was designed to provide uniform heating. The three red circles indicate the location of the temperature sensors. (e) Scanning electron micrograph (SEM) of test device 1 showing pillar diameter $(D)$, height $(H)$, and center-to-center spacing $(L)$.

\section{Experimental methodology}

The device holder was made from a high temperature plastic (Ultem). It consists of two parts: top cover (Fig. 3a) and bottom fixture (Fig. 3b). The center $1 \times 1 \mathrm{~cm}^{2}$ of the top cover was cut out for evaporation. Additionally, a secondary water reservoir was incorporated on the top cover by milling a $2 \mathrm{~mm}$ deep groove surrounding the center cut out section. The purpose of this reservoir was to maintain the primary reservoir full at all times. During the experiment, excess water was delivered to the secondary reservoir. After filling the primary reservoir, the excess water leaves the secondary reservoir through the exit port. The two-reservoir design enabled passive liquid transport where the microstructured area syphons only the required amount of water from the primary reservoir to sustain evaporation. This strategy minimized device flooding and avoided subsequent boiling. Consequently, we did not observe nucleate boiling in any of our experiments. Spring loaded pogo-pins (HPA-1D and SPR-1W, Everett Charles Technologies) were press fit into the bottom fixture to establish electrical contact between the power source and the heater and sensors via $2.5 \times 2.5 \mathrm{~mm}^{2}$ contact pads. The assembly (Fig. 3c) was held together by four threaded bolts after sandwiching the test device between the top cover and bottom fixture. 

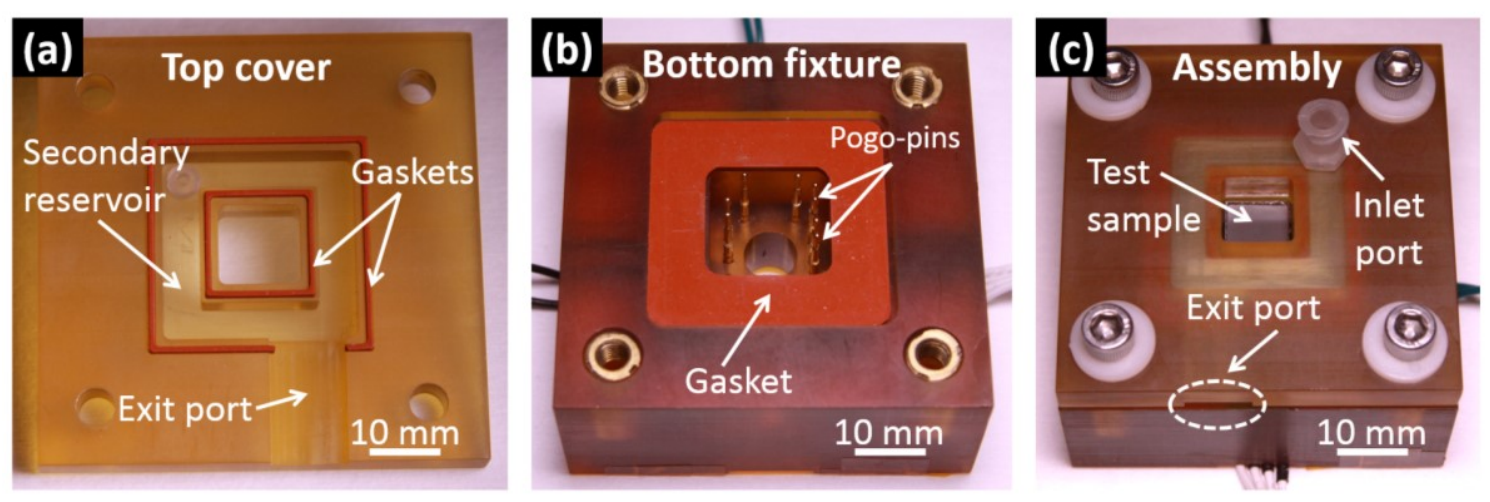

Fig. 3. Device holder (a) top cover, (b) bottom fixture, and (c) assembly. The test device was pressed against spring-loaded pogo-pins by aligning the microstructured surface of the device with the $1 \times 1 \mathrm{~cm}^{2}$ cutout section of the top cover. Water was supplied to the secondary reservoir using a chemically inert polyvinyl chloride (PVC) plastic tubing. Electrical wires connect the pogo-pins with an external power source for heating and temperature sensing.

A schematic of the experimental setup with the main components including the custom built stainless steel environmental chamber $\left(16 \times 16 \times 16 \mathrm{in}^{3}\right)$ and the liquid supply mechanism is shown in Fig. 4. A standard cleaning procedure was followed before each experiment where the test devices were thoroughly rinsed using acetone, methanol, isopropanol (IPA), and de-ionized (DI) water. This was followed by blow drying with compressed nitrogen and a 30 min oxygen plasma treatment in an oxygen environment (PDC-001, Harrick Plasma). The assembly $\left(2.4 \times 2.4 \times 1.25 \mathrm{in}^{3}\right)$ (Fig. $\left.3 \mathrm{c}\right)$ was placed on a z-stage inside the environmental chamber and the entire system was pumped down using a vacuum pump (Pascal 2010 SD, Adixen) before the start of the experiments to remove all noncondensable gases. A resistive rope heater which was controlled using a voltage 
regulator was wrapped around the exterior of the environmental chamber beneath an insulation layer to maintain a constant chamber temperature. The environmental chamber was maintained near saturated conditions by injecting DI water into the evacuated environmental chamber and letting it reach the saturation pressure. The liquid feedthrough consists of a $1 / 4$ " outer diameter stainless steel tube that was fed into the chamber via a KF adaptor port that served as the flow line for the incoming water into the environmental chamber. High purity DI water (Chromasolv for HPLC, Sigma-Aldrich) which was stored in a canister outside the environmental chamber was used as the working fluid. The water was degassed via vigorous boiling for several minutes to force dissolved gases to escape from the liquid domain and venting the pressurized gas/vapor mixture multiple times. The water temperature inside the canister was measured by inserting a calibrated 12" J-type thermocouple. All thermocouples that were used in our experiments were calibrated prior to experiment using a refrigerated water bath heat exchanger with $\pm 0.05^{\circ} \mathrm{C}$ accuracy (Lauda RE200, Lauda-Brinkmann). The water vapor pressure inside the canister matched the value of the saturated water pressure from the NIST database [24] at the measured water temperature inside the canister, ensuring the absence of dissolved noncondensable gases in the water supply. For this study, the water inside the canister was maintained at $\approx 60^{\circ} \mathrm{C}$ via a closed-loop temperature feedback system using a $1 / 16$ DIN ramp/soak Proportional-Integral-Derivative (PID) controller (CN7823, Omega Engineering) and corresponding saturation pressure $\approx 20 \mathrm{kPa}$, while the environmental chamber was maintained at $\approx 24{ }^{\circ} \mathrm{C}$ and corresponding saturation pressure $\approx 3 \mathrm{kPa}$. The pressure difference between the canister and the chamber $(\approx 17 \mathrm{kPa})$ was utilized to 
transport water from the canister to the environmental chamber and secondary reservoir by overcoming the hydrostatic head and the viscous losses in the valve and tubing. The water supply from the canister $\left(\approx 60^{\circ} \mathrm{C}\right)$ whose flow rate was measured using a liquid flow meter (L-50CCM-D, Alicat Scientific) (V, Fig. 4) was actively cooled to $\approx 24{ }^{\circ} \mathrm{C}$ before entering the environmental chamber using a refrigerated water bath heat exchanger (Lauda RE200, Lauda-Brinkmann) (Water chiller, Fig. 4). The amount of water that was syphoned onto the microstructured surface actively responded to heating, i.e., the liquid transport mechanism adjusts itself based on the heat flux and mass loss via evaporation.

The chamber ambient temperature was measured by inserting a calibrated J-type thermocouple ( $T$, Fig. 4) via a thermocouple feedthrough. A capacitance manometer (740C Baratron, MKS Instruments, Inc.) was used to monitor and record the chamber pressure ( $P$, Fig. 4). The temperature and pressure of the environmental chamber matched the NIST database [24] for saturated conditions. During the experiments, the water vapor that evaporated from the test device was allowed to condense on the internal walls of the environmental chamber. To maintain the chamber vapor pressure fairly constant $(\approx 3000 \pm 200 \mathrm{~Pa})$, an additional condensing surface was created by circulating water $\left(\approx 10-15{ }^{\circ} \mathrm{C}\right)$ through a $1 / 4^{\prime \prime}$ outer diameter copper tube using a water-to-water heat exchanger (Neslab System-III, Thermo Fisher Scientific). The condensate on the outside of the copper tube and the inside walls of the environmental chamber along with the excess water from the secondary reservoir was collected at the bottom of the environmental chamber. The condensate was then drained through the drain valve at the end of each experiment and the chamber was made ready for the next 
experimental run. The environmental chamber has viewing ports for in situ visualization of the micropillar wick and the evaporation process. This enabled us to visually detect and monitor the incipience and radial growth of a dry island during dryout and thermal run away. Thermal run away is characterized by a sudden temperature spike which can be identified from the temporal temperature data. In addition to visual monitoring of the experiments, images were acquired at 1000 frames per second using a high speed camera (Phantom v7.1, Vision Research). All relevant data were channeled into an analog input data acquisition system (cDAQ-9174, National Instruments) via a custom made LabVIEW script [25] which was interfaced with a computer.

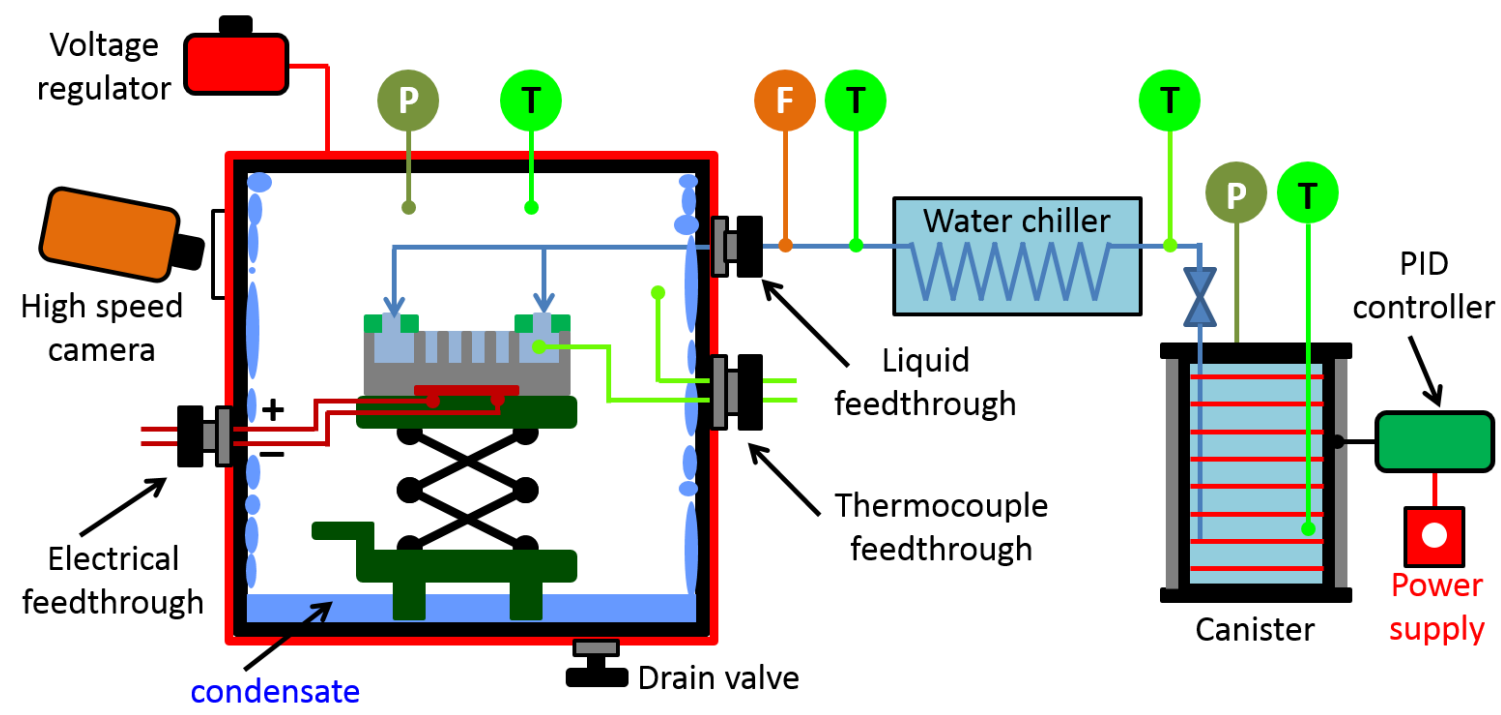

Fig. 4. Schematic (not-to-scale) of the experimental setup. The environmental chamber and the canister were maintained near saturated conditions (i.e., saturation temperature and corresponding pressure). This was confirmed by matching the temperature and pressure measurements with the NIST database. The water in the canister $\left(\approx 60{ }^{\circ} \mathrm{C}\right)$ was actively cooled to the chamber temperature $\left(\approx 24^{\circ} \mathrm{C}\right)$ using a water bath heat exchanger. 
During experiments, temperature, pressure, and flow rate were measured using thermocouple $(T)$, pressure gage $(P)$, and liquid flow meter $(F)$. The canister was maintained at constant temperature using a closed-loop PID controller. The surface of the micropillar wick was visually monitored for dryout in situ during experiments.

A DC power source (N5752A, Agilent Technologies) was used to supply the voltage that was required for heating and temperature sensing via an electrical feedthrough. The heating power was calculated from the power source voltage $\left(V_{P S}\right)$ and current $\left(I_{P S}\right)$ which were measured using a digital multimeter (Model 2000, Keithley Instruments). The heat flux $(q ")$ was calculated for the $1 \times 1 \mathrm{~cm}^{2}$ heated area $(A)$ as

$$
q^{\prime \prime}=\frac{V_{P S} I_{P S}}{A}
$$

The temperature difference $(\Delta T)$ between the solid wall at the base of the micropillars ( $\left.T_{\text {wall }}\right)$ and the saturation chamber temperature $\left(T_{\text {sat }}\right)$ was calculated by assuming one-dimensional (1D) heat conduction through the silicon substrate as given by

$$
\Delta T=T_{\text {wall }}-T_{\text {sat }}=\left(T_{\text {back }}-T_{\text {sat }}\right)-q^{\prime \prime}\left(\frac{t_{\text {SiO2 } 2}}{k_{\text {SiO } 2}}+\frac{t_{s u b}}{k_{s u b}}\right)
$$

where $T_{\text {back }}$ is the backside temperature which was measured by the temperature sensors, and $t$ and $k$ are the thickness and thermal conductivity of the materials indicated by the subscript, i.e., silicon dioxide and silicon substrate, respectively. The thicknesses of the electrically insulating silicon dioxide layer and the substrate were $\approx 1 \mu \mathrm{m}$ and $\approx 650 \mu \mathrm{m}$, respectively. 


\section{Experimental Results}

This work experimentally characterizes steady state thin-film evaporation in the absence of nucleate boiling from silicon micropillar wicks where liquid transport was limited by capillarity. Typical temporal data for device 1 is shown in Fig. 5a-b. The water entered the environmental chamber at saturated condition, i.e., the temperature of the incoming water matched the chamber saturation temperature (Chamber and Incoming water, Fig. 5a). During the experiments, the heat flux was increased in a stepwise manner (Fig. 5b) such that steady state evaporation was sustained for a minimum of $200 \mathrm{~s}$ at each heat flux (Fig. 5a-b). Steady state evaporation was assumed when the change in temperature reading did not exceed $0.2^{\circ} \mathrm{C} / \mathrm{min}$. The local temperature readings from the three sensors and the average temperature from the heater were near identical. The heater was calibrated and was used to measure the average temperature over the heated $1 \times 1 \mathrm{~cm}^{2}$ microstructured area in addition to providing the heating power. The near identical temperature readings from the sensors and heater confirmed that the microstructured surface was nearly isothermal during thin-film evaporation [1]. For brevity, the temporal data for only sensor 2 (Sensor 2, Fig. 5a) and the heater (Heater, Fig. 5a) are shown. Thermal runaway and the associated spike in temperature (Time $\approx 3200 \mathrm{~s}$, Fig. 5a-b) was observed when dryout occurred at the center of the microstructured area ( $q^{\prime \prime} \approx 46 \mathrm{~W} / \mathrm{cm}^{2}$ at $\left.\Delta T \approx 19{ }^{\circ} \mathrm{C}\right)$ (Fig. 5c). Furthermore, when the surface dries out, the heat transfer mechanism changes from evaporation (phase change, most efficient) to convection (single phase, less efficient). The dry island that forms at the center of the heated area can be observed by the naked eye and grows radially outwards. 
We did not visually observe boiling or bubble nucleation in any of our experiments. The experimental results (both the temporal data as well as dryout heat flux) were repeatable and independent of the flow rate. For example, when the flow rate was doubled from 10 to $20 \mathrm{~mL} / \mathrm{min}$, both the temperature and dryout heat flux remained unaffected (Fig. 5c), confirming the role of the secondary reservoir with an exit port to flush out the excess water. This ensured the role of capillary wicking as the sole liquid transport mechanism within the micropillar wick. Unless stated otherwise, the error bars in Fig. 5c and elsewhere in this study were obtained by combining the random (statistical, one standard deviation) and system errors. The system error for temperature measurement was obtained via standard error propagation analysis [26] from the measured excitation voltage and current and calibration curve. Similarly, the error bar on the heat flux was obtained from the uncertainty in measuring the power source voltage, current and the evaporation area. The data points A and B in Fig. $5 c$ correspond to steady state thin-film evaporation at $\approx 20 \mathrm{~W} / \mathrm{cm}^{2}$ (Fig. $5 \mathrm{~d}$ ) and initiation of dryout at $\approx 46 \mathrm{~W} / \mathrm{cm}^{2}$ (Fig. 5 e), respectively. 

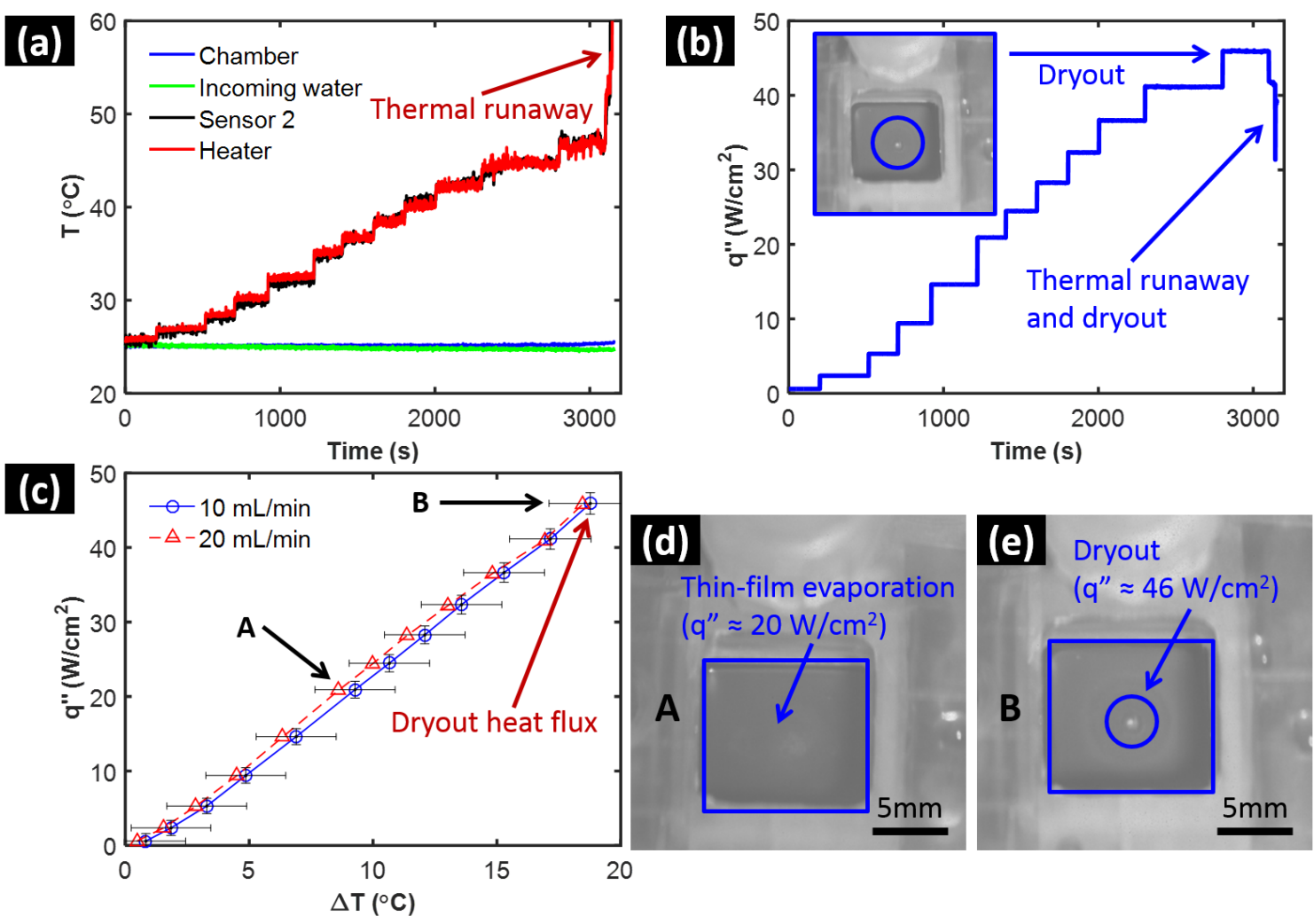

Fig. 5. (a) Temperature as a function of time, (b) heat flux as a function of time, and

(c) heat flux as a function of the temperature difference between the substrate wall and the chamber. Optical images of the test device during (d) steady state thin-film evaporation at $\approx 20 \mathrm{~W} / \mathrm{cm}^{2}$, and (e) dryout and thermal run away at $\approx 46 \mathrm{~W} / \mathrm{cm}^{2}$ for device 1. When the pressure loss due to viscosity and inertia exceeds the capillary pumping pressure, water is not supplied fast enough to compensate for the liquid loss via evaporation and the center of the microstructured heated area dries out due to liquid starvation.

Sensible, convective, and ohmic heating losses were characterized experimentally. The sensible heat loss was estimated by measuring the flow rate and the temperature of the incoming and outgoing water in the secondary reservoir (Incoming water and 
Outgoing water, Fig. 6a-b). The water temperature was measured using fine gage calibrated J-type thermocouples (IRCO-003, Omega Engineering). The convection heat loss was estimated conservatively for a $10 \mathrm{~W} / \mathrm{m}^{2} \cdot \mathrm{K}$ heat transfer coefficient inside the saturated environmental chamber which was maintained at low pressure $(\approx 3 \mathrm{kPa})$. Lastly, the heat loss in the lead wires, pogo-pins, and electrical feedthrough was estimated by measuring the electrical resistance $(r)$ and calculating the $i^{2} r$ ohmic loss where $i$ is the current. The combined heat loss via sensible, convection, and ohmic was $\leq 2 \%$ of the input heating power. This heat loss was deducted from the input power in all the heat fluxes reported in this study.
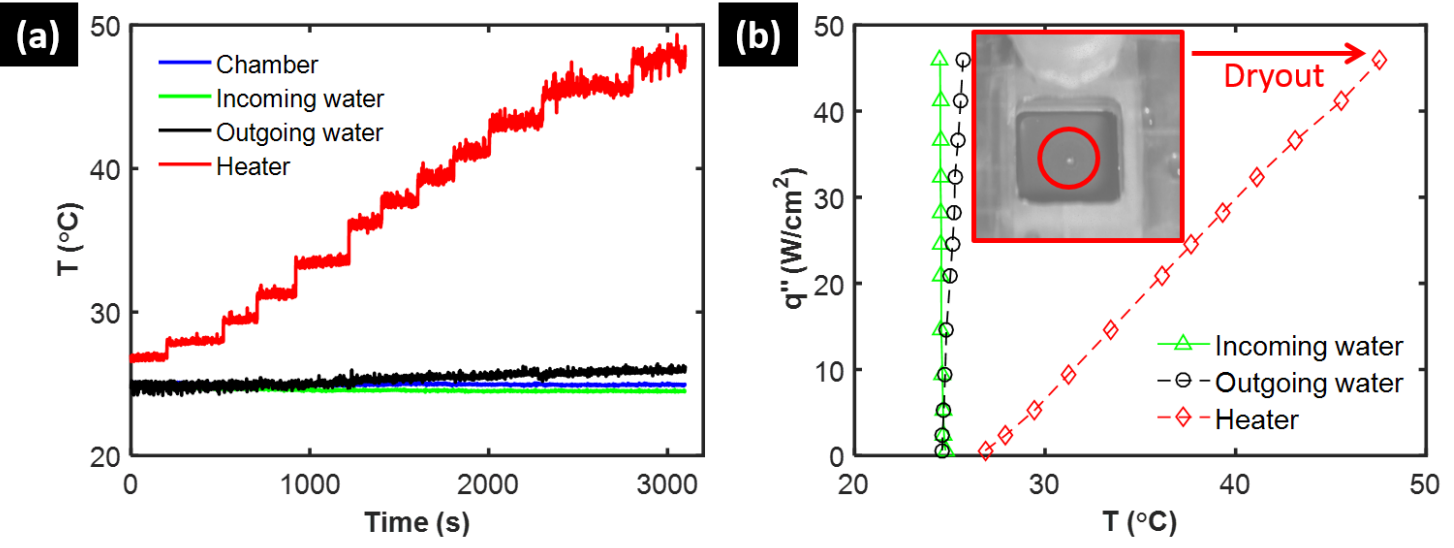

Fig. 6. Heat loss characterization. (a) Temperature as a function of time, and (b) heat flux as a function of temperature for device 1 . The heat loss ( $\leq 2 \%$ of the input power) accounts for sensible, convective and ohmic losses.

\section{Modeling}

We developed a detailed model for capillary-limited thin-film evaporation from well-defined micropillar wicks. We modeled the liquid transport, phase change heat 
transfer, permeability, capillary pressure (via meniscus shape and receding contact angle), and thermal resistance separately. The different sub-models were combined to obtain a unified semi-analytical model that can predict both the dryout heat flux as well as the substrate wall temperature.

\subsection{Liquid transport and heat transfer}

Fluidic and thermal transport were modeled for a two-dimensional (2D) microstructured surface (Fig. 7a). We conserve mass, momentum, and energy in the liquid domain shown by the control volume (red dashed box, Fig. 7b) by assuming uniform evaporation from the top liquid-vapor interface. Liquid transport was driven by the pressure gradient that was created as a result of the variation in the curvature of the liquid meniscus between the center and edge of the microstructured surface [15]. Dryout commences when the viscous losses through the micropillar wick exceeds the capillary pressure that can be generated owing to the meniscus shape. 


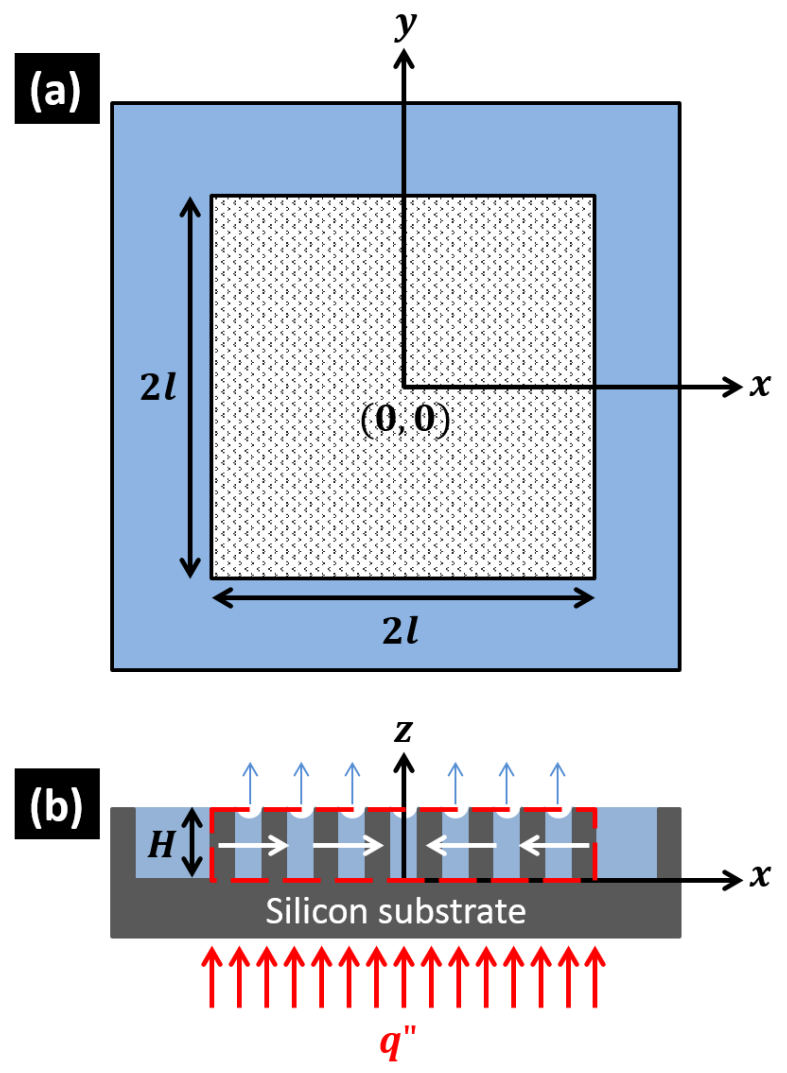

Fig. 7. Schematic (not-to-scale) of the modeling domain. (a) Top view, and (b) side view of the micropillar wick and the surrounding water. Mass, momentum, and energy were conserved for the liquid domain within the micropillar wick as shown by the control volume in red dashed box in (b).

All of the heating power that was supplied to the backside of the test device was assumed to be utilized for phase change with no sensible heating. Consequently, the conservation of energy can be written as

$$
q^{\prime \prime}=\rho_{l} \bar{u}_{z} h_{f g}
$$

where $q$ " is a prescribed uniform heat flux, $\rho_{l}$ is the density of the evaporating liquid, $h_{f g}$ is the latent heat of vaporization, and $\bar{u}_{z}$ is the average velocity of the evaporating 
liquid in the z-direction. The conservation of mass for incompressible fluid flow through the porous media can be expressed using the continuity equation as

$$
\frac{\partial \bar{u}_{x}(x, y)}{\partial x}+\frac{\partial \bar{u}_{y}(x, y)}{\partial y}+\frac{q^{\prime \prime}}{H \rho_{l} h_{f g}}=0
$$

where $\bar{u}_{x}$ and $\bar{u}_{y}$ are the average velocity in the $x$ - and $y$-directions respectively. By assuming laminar flow and using the lubrication approximation to simplify the expression, the momentum equation for flow in porous media (Brinkman equation) [27] in 2D ( $x$ - and $y$-direction) is given by

$$
\begin{aligned}
& \frac{\partial^{2} u_{x}(x, y, z)}{\partial z^{2}}=\frac{\varepsilon}{\mu_{l}} \frac{\partial \mathrm{P}(x, y)}{\partial \mathrm{x}}+\frac{\varepsilon u_{x}(x, y, z)}{K}, \\
& \frac{\partial^{2} u_{y}(x, y, z)}{\partial z^{2}}=\frac{\varepsilon}{\mu_{l}} \frac{\partial \mathrm{P}(x, y)}{\partial \mathrm{y}}+\frac{\varepsilon u_{y}(x, y, z)}{K},
\end{aligned}
$$

where $\mathrm{P}(x, y)$ is the pressure below ambient, $u_{x}(x, y, z)$ and $u_{y}(x, y, z)$ are the $x$ - and $y$-direction velocities, respectively, $\mu_{l}$ is the dynamic viscosity of the liquid, $\varepsilon$ is the porosity of the micropillar wick $\left(\varepsilon=1-\pi D^{2} / 4 L^{2}\right)$, and $K$ is the permeability of the porous media. The boundary conditions for the momentum equation are the no-slip boundary condition at the base of the micropillar wick $(z=0)$ and shear-free surface at the top of the liquid meniscus $(z=H)$ as described by 


$$
\begin{gathered}
\left.u_{x}(x, y, z)\right|_{z=0}=0, \\
\left.\frac{\partial u_{x}(x, y, z)}{\partial z}\right|_{z=H}=0, \\
\left.u_{y}(x, y, z)\right|_{z=0}=0, \\
\left.\frac{\partial u_{y}(x, y, z)}{\partial z}\right|_{z=H}=0 .
\end{gathered}
$$

The expression for the capillary-limited dryout heat flux can be obtained by solving Eqs. (3)-(5) simultaneously using the boundary conditions in Eq. (6) as

$$
q^{\prime \prime} \approx \frac{10}{3}\left(\frac{H K P_{c a p}}{l^{2}}\right)\left(1-\frac{\tanh (H \beta)}{(H \beta)}\right)\left(\frac{\rho_{l} h_{f g}}{\mu_{l}}\right),
$$

where $P_{c a p}$ is the capillary pressure below ambient at the center of the microstructured surface, $l$ is the dryout length, and $\beta$ is a geometric parameter $(\beta=\sqrt{\varepsilon / K})$. A detailed mathematical derivation is shown in Appendix A.1. Equation (7) shows that the dryout heat flux is directly proportional to the micropillar wick thickness and permeability, but inversely proportional to the square of the dryout length. The term in the second parenthesis in Eq. (7) varies between 0.8 and 1.0 depending on the dimensions of the micropillars $(D, H$, and $L)$ and hardly affects the linear dependence between dryout heat flux and micropillar wick thickness. Furthermore, Eq. (7) shows that the dryout heat flux is a function of the dimensions of the micropillars and thermophysical properties of the working fluid. 


\subsubsection{Permeability}

The permeability of the micropillar wick was estimated by modifying the numerical model for 2D laminar flow of infinitely long arrays of parallel cylinders [28]. The 2D model assumes a flat liquid meniscus and consequently overestimates the permeability by as much as $100 \%$ [29]. However, the shape of the evaporating liquid meniscus in our experiments varies from the edge of the microstructured area (nearly flat) to the center (most curved). As a result, the actual micropillar wick thickness $\left(H^{*}\right)$ through which liquid is transported is smaller than the nominal thickness $(H)$ (Fig. 8a).
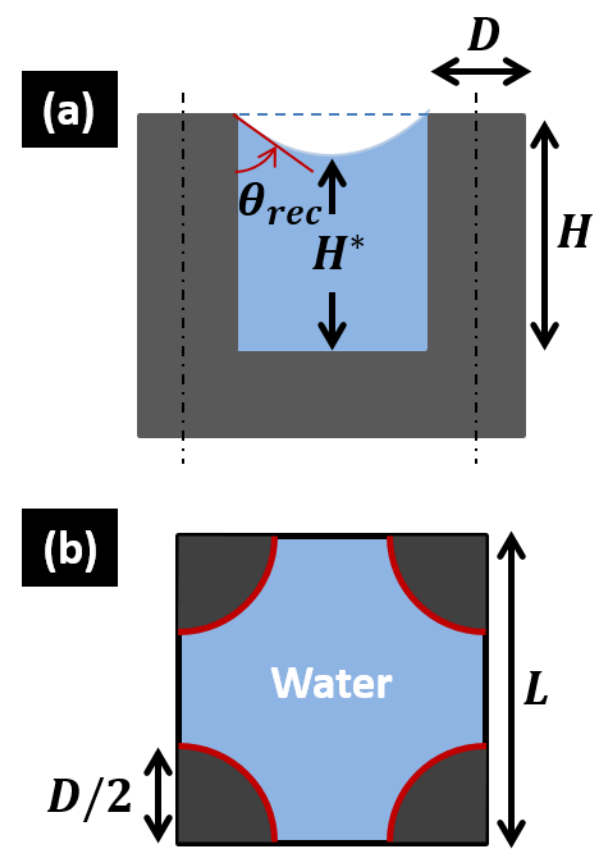

Fig. 8. Schematic (not-to-scale) of a unit cell of cylindrical micropillars in a square pattern. (a) Side, and (b) top view. The solid red quadrants in (b) represent the three-phase contact line where the liquid contacts the micropillars along the circumference. 
Assuming that the meniscus is part of a spherical cap, the actual micropillar wick thickness and the nominal thickness are related through the receding contact angle $\left(\theta_{\text {rec }}\right)$ which can be given by

$$
H^{*}=H-\frac{(\sqrt{2} L-D)\left(1-\sin \theta_{r e c}\right)}{2 \cos \theta_{r e c}}
$$

An effective micropillar wick thickness $\left(H_{e f f}\right)$ for liquid transport is defined by assuming a linear variation in micropillar wick thickness from the edge of the microstructured area to the center as

$$
H_{e f f}=\frac{H+H^{*}}{2}
$$

This effective height is used to accurately estimate the effective permeability $\left(K_{\text {eff }}\right)$ which accounts for the three-dimensional (3D) variation in permeability as

$$
\begin{gathered}
K_{e f f}=K_{2 D}\left\{1-\frac{\exp \left(2 \beta H_{e f f}\right)-1}{\beta H_{e f f}\left[\exp \left(2 \beta H_{e f f}\right)+1\right]}\right\} \Lambda_{1} \Lambda_{2}, \\
\Lambda_{1}=\frac{H_{e f f}}{H}, \Lambda_{2}=\frac{H_{e f f}+\xi}{H+\xi}, \xi=\frac{\varepsilon D}{4(1-\varepsilon)^{\prime}}
\end{gathered}
$$

where $K_{2 D}$ is the permeability from Sangani and Acrivos [28]. The expression in the bracket is a correction factor for the porous nature of the medium while $\Lambda_{1}$ and $\Lambda_{2}$ are correction factors that account for the variation in wetted area and the channel cross-sectional area, respectively [29]. 


\subsubsection{Capillary pressure}

Depending on the heat flux and the evaporation rate, the liquid meniscus dynamically adjusts its curvature to compensate for the mass loss via evaporation. Consequently, steady state thin-film evaporation was maintained in all our experiments. The liquid meniscus at the center of the wick is near flat for low heat fluxes whereas the curvature increases as the heat flux increases [30]. When the contact angle between the liquid-vapor interface and the pillar wall reaches the receding contact angle, the liquid meniscus starts to recede and the microstructured area dries out. During steady state evaporation and before the liquid meniscus starts to recede, the forces due to capillary pressure (the pressure difference between the vapor and liquid side) and surface tension are in mechanical equilibrium. The surface tension force acts around the circumference of the pillar, i.e., along the three-phase contact line of the meniscus (highlighted in red, Fig. 8b). The capillary pressure which acts on the projected area of the curved liquid meniscus $\left(L^{2}-\pi D^{2} / 4\right)$ (Fig. $8 \mathrm{~b}$ ) can be analytically solved from a force balance at the receding meniscus as

$$
P_{c a p}=\frac{4 \sigma_{L V} \cos \theta_{r e c}}{D\left\{\frac{4}{\pi}\left(\frac{L}{D}\right)^{2}-1\right\}},
$$

where $\sigma_{L V}$ is the liquid-vapor surface tension. 


\subsubsection{Receding contact angle}

The receding contact angle was estimated by comparing experimentally measured laser interferometry data with Surface Evolver (SE) simulation [31]. When a monochromatic laser beam interacts with thin curved liquid meniscus, bright and dark fringes (Fig. 9a) form due to interference of the incident and reflected light rays [30]. The three-dimensional (3D) meniscus shape can be reconstructed from the fringe pattern. Details of the experimental setup and characterization technique is discussed in Appendix A.2.

The interference fringes in the diagonal $A B$ (Fig. 9a, points $0,1,2,3,4$ ) and lateral CB (Fig. 9a, points $a, b, c$ ) directions for a receding meniscus [32] were compared against the meniscus shape obtained from SE for various contact angles. The SE simulation gives varying liquid meniscus shapes based on the contact angle and the solid-liquid fill volume ratio used for simulation. The interference fringe in the diagonal direction $A B$ (Fig. 9b, points $0,1,2,3,4$ ) matched reasonably well with the meniscus shape obtained from SE for $65^{\circ}$ contact angle with $\approx 6 \%$ RMSE. Similarly, the interference fringe in the lateral direction $\mathrm{CB}$ (Fig. 9c, points $a, b, c$ ) matched reasonably well with the meniscus shape obtained from SE for $75^{\circ}$ contact angle with $\approx 4 \%$ RMSE. The average receding contact angle $\approx 70^{\circ}$ was used to estimate the capillary pressure in Eq. (11). We attribute the high receding contact angle to the presence of a hydrophobic polymer (Octafluorocyclobutane, $\mathrm{C}_{4} \mathrm{~F}_{8}$ ) that remained on the sidewalls of the micropillars due to the time-multiplexed DRIE. We have verified the presence of carbon $(\approx 11 \%)$ and fluorine $(\approx 2 \%)$ on the sidewalls of the micropillars via $\mathrm{x}$-ray photoelectron spectroscopy (XPS) 
(Fig. 9d). The horizontal error bars for the interference data were obtained from the in-plane width of the dark fringe while the vertical error bars were obtained from the out-of-plane height difference between neighboring dark and bright fringes.
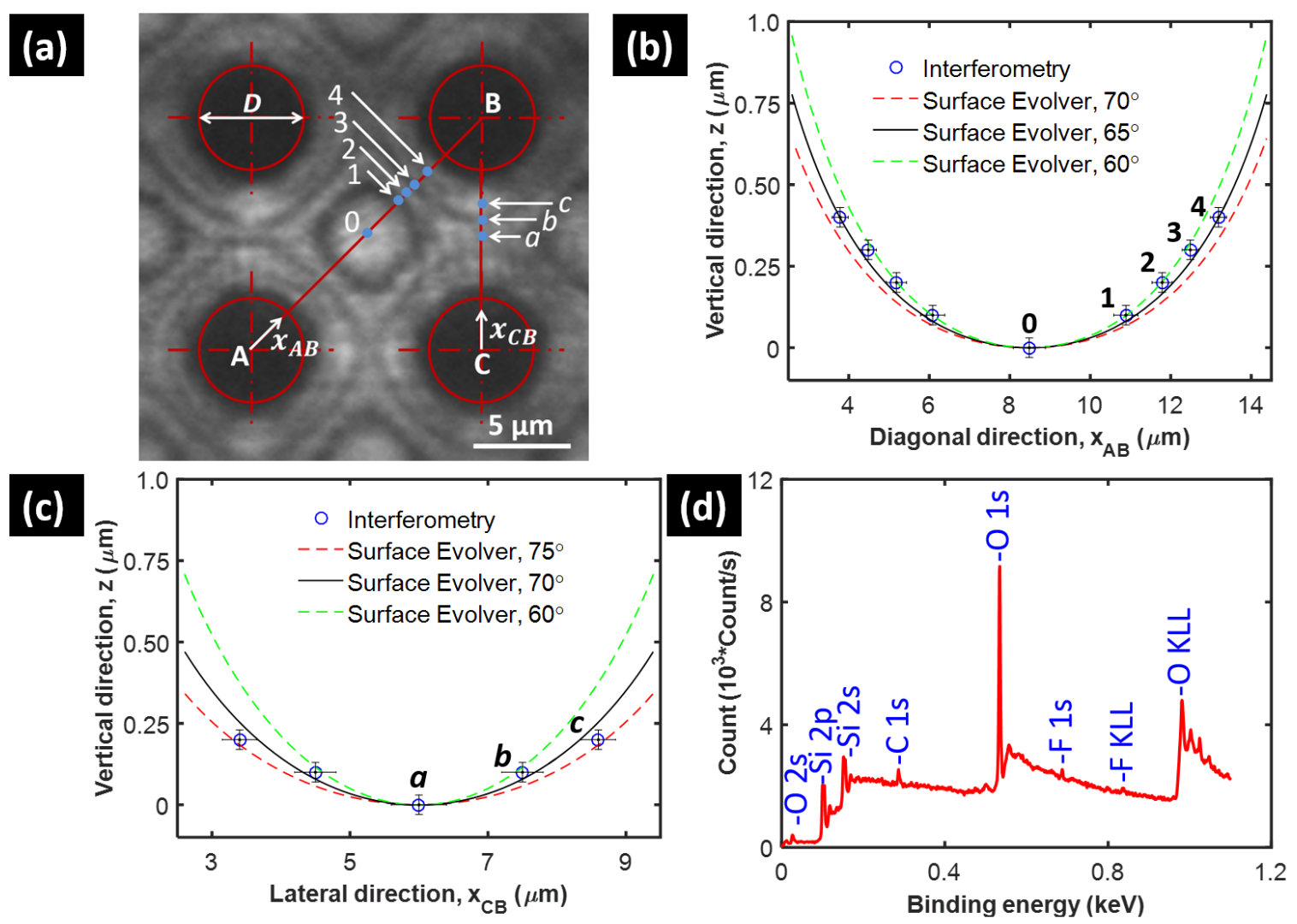

Fig. 9. (a) Representative interference fringe pattern, (b) receding contact angle along $A B$ direction, (c) receding contact angle along CB direction, and (d) XPS for device 1 . The side wall of the pillars coincide with the vertical axis in (b) and (c) (i.e., the right and left z-axis). Due to measurement limitation of the interference technique, the fringe pattern near the pillars did not have enough contrast (fuzzy) and were difficult to resolve accurately.

The final expression for the capillary-limited dryout heat flux was obtained by replacing the nominal micropillar wick thickness and permeability in Eq. (7) by the 
effective micropillar wick thickness from Eq. (9) and effective permeability from Eq. (10). After replacing for the capillary pressure from Eq. (11) and rearranging some of the terms, the dryout heat flux is given by

$$
\begin{gathered}
q^{\prime \prime} \approx(40 / 3) \psi M \cos \theta_{\text {rec }} \\
\psi=\frac{H_{e f f} K_{e f f}\left(1-\frac{\tanh \left(H_{e f f} \beta_{e f f}\right)}{\left(H_{e f f} \beta_{e f f}\right)}\right)}{l^{2} D\left[\left(\frac{4}{\pi}\right)\left(\frac{L}{D}\right)^{2}-1\right]}, \beta_{e f f}=\sqrt{\frac{\varepsilon}{K_{e f f}}}, M=\frac{\sigma_{L V} \rho_{l} h_{f g}}{\mu_{l}},
\end{gathered}
$$

where $M$ is the figure of merit which is a measure of the capillary-limited maximum heat carrying capacity of the working fluid [10]. The figure of merit, which has a unit of heat flux $\left(\mathrm{W} / \mathrm{m}^{2}\right)$ is a common performance metric and one of the selection criteria for the working fluid in heat pipe technology. For DI water at $24{ }^{\circ} \mathrm{C}$ saturation temperature, $M \approx 1.9 \times 10^{11} \mathrm{~W} / \mathrm{m}^{2}$ and this value increases until the temperature exceeds $\approx 130{ }^{\circ} \mathrm{C}[33]$. The effect of the micropillar wick dimensions $(D, H$, and $L)$ on the heat transport capacity is lumped into the dimensionless parameter $\psi$. Equation (12), which can easily be adopted for other working fluids, predicts the capillary-limited evaporative dryout heat flux in addition to identifying the important parameters that limit thermal transport in micropillar wicks. Small length-scale micropillar wicks (high capillary pressure and large extended meniscus area) and yet highly permeable microstructured surfaces are desired for maximizing the dryout heat flux. 


\subsection{Thermal resistance}

Since silicon pillars have a higher thermal conductivity $\left(k_{S i} \approx 152 \mathrm{~W} / \mathrm{m} \cdot \mathrm{K}\right)$ than the bulk liquid water $\left(k_{w} \approx 0.6 \mathrm{~W} / \mathrm{m} \cdot \mathrm{K}\right)$, the heating power that is supplied to the backside of the test device is conducted through the silicon substrate and then primarily through the pillars to induce evaporation at the liquid-vapor interface near the pillar top (Fig. 10a). The thickness of the evaporating thin-film region along the circumference of the pillars is only few microns [11]. Consequently, most of the heat is conducted through the thin-film region [34] and spreads over the liquid-vapor interface before causing phase change. The resistance through the bulk liquid $\left(R_{\text {bulk }}\right)$ is at least one order of magnitude larger than the combined constriction $\left(R_{c o n}\right)$, pillar $\left(R_{p}\right)$, thin-film $\left(R_{T F}\right)$, and spreading $\left(R_{s p}\right)$ resistances (Fig. 10b). Consequently, the resistance network can be simplified to create an equivalent thermal resistance where the substrate, constriction, pillar, thin-film, spreading, and interfacial resistances are in series as shown in Fig. 10c by ignoring the bulk resistance and accounting for the phase change interfacial resistance $\left(R_{\text {int }}\right)$. 

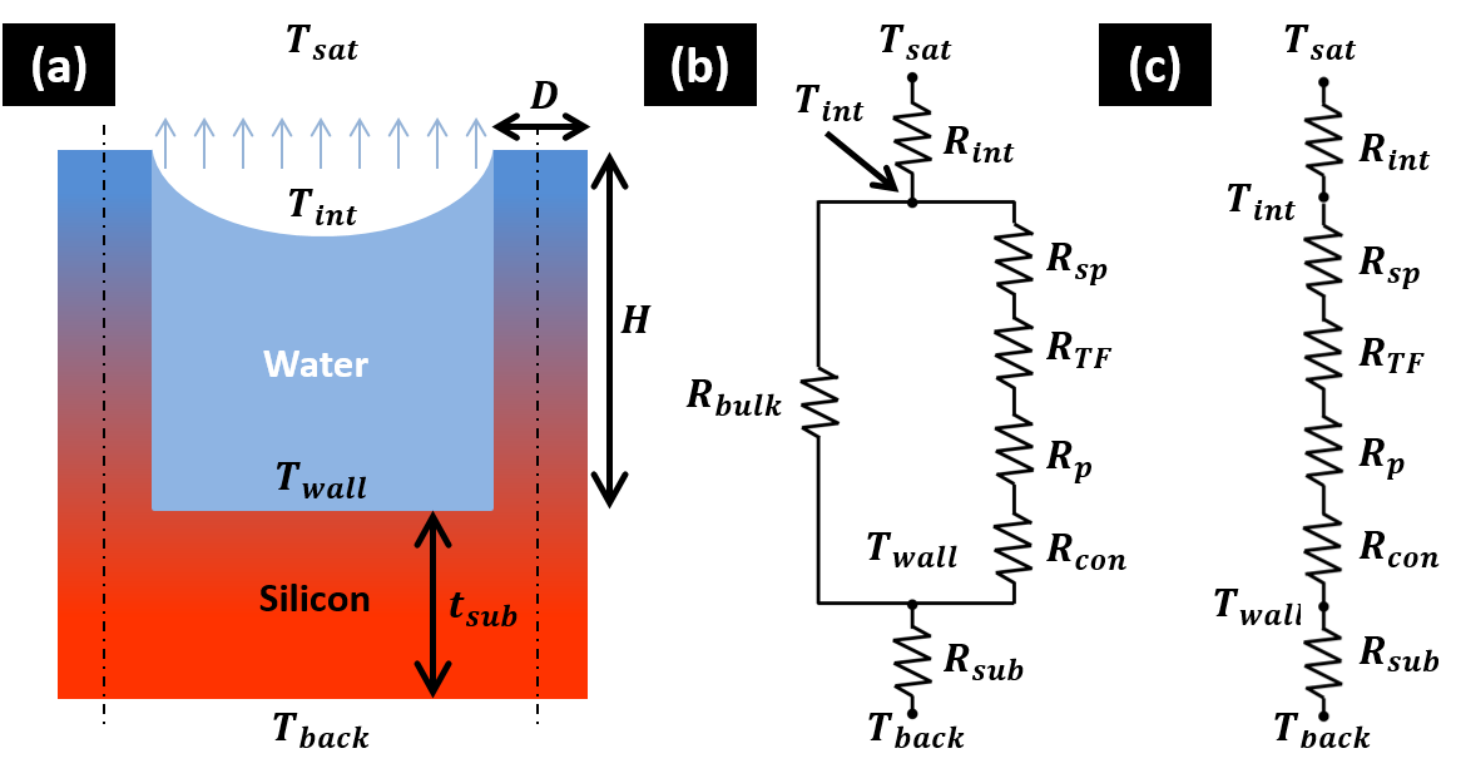

Fig. 10. (a) Schematic (not-to-scale) of a unit cell showing the heat conduction path through the substrate-liquid domain. (b) Heat conduction path through the bulk liquid and the solid substrate and the associated thermal resistances. (c) One-dimensional equivalent thermal resistance model.

Assuming 1D heat conduction through the silicon dioxide layer and substrate and neglecting lateral heat spreading through the solid, the substrate resistance $\left(R_{\text {sub }}\right)$ can be estimated as

$$
R_{\text {sub }}=\frac{t_{\text {SiO2 }}}{N A_{\text {cell }} k_{\text {SiO2 } 2}}+\frac{t_{\text {sub }}}{N A_{\text {cell }} k_{\text {Si }}},
$$

where $N$ is the number of pillars in $1 \times 1 \mathrm{~cm}^{2}$ area, and $A_{\text {cell }}$ is the area of a unit cell $\left(A_{\text {cell }}=L^{2}\right)$. The number of pillars can be calculated by dividing the microstructured area (A) by the unit cell area, i.e., $N=A / A_{\text {cell }}$. Neglecting fin effect and convection losses from the side walls of the pillars, the pillar resistance can be approximated by 


$$
R_{p}=\frac{H}{N A_{p} k_{S i}}
$$

where $A_{p}$ is the pillar area in a unit cell $\left(A_{p}=\pi D^{2} / 4\right)$. The constriction and spreading resistances were estimated for adiabatic boundary conditions [35]. The thin-film resistance can be estimated by assuming heat conduction through the thin-film region near the three-phase contact line as

$$
R_{T F}=\frac{t_{T F}}{A_{T F} k_{w}}
$$

where $t_{T F}$ and $A_{T F}$ are the thin-film thickness and area, respectively. The thin-film area was obtained analytically by calculating the area of $a \approx 1 \mu \mathrm{m}$ thick liquid film surrounding the micropillars for a $70^{\circ}$ receding contact angle. Finally, the interfacial resistance was estimated using the Schrage equation [36] based on the experimentally obtained average accommodation coefficient $(\approx 0.08)$ as

$$
R_{\text {int }}=\frac{1}{A_{\text {int }}}\left(\frac{2-\chi}{2 \chi}\right)\left(\frac{T_{v} v_{l v}}{h_{l v}{ }^{2}}\right)\left(\frac{2 \pi \bar{R} T_{v}}{\bar{M}}\right)^{1 / 2}\left(1-\frac{P_{v} v_{l v}}{2 h_{l v}}\right)^{-1}
$$

where $\chi$ is the accommodation coefficient for our experiments, $h_{l v}$ and $v_{l v}$ are the enthalpy and specific volume difference between the vapor and liquid phases, respectively, $T_{v}$ and $P_{v}$ are the vapor temperature and pressure, respectively, $\bar{M}$ is the molar mass of water $(0.01801 \mathrm{~kg} / \mathrm{mol}), \bar{R}$ is the universal gas constant $(8.314 \mathrm{~J} / \mathrm{mol} \cdot \mathrm{K})$, and $A_{\text {int }}$ is the area of the evaporating liquid-vapor interface. The liquid-vapor interfacial area was estimated from SE simulation for a $70^{\circ}$ contact angle. 
Combining the individual resistances, the one-dimensional equivalent thermal resistance $\left(R_{e q}\right)$ can be written as

$$
R_{\text {eq }}=R_{\text {sub }}+R_{\text {con }}+R_{p}+R_{T F}+R_{\text {sp }}+R_{\text {int }}
$$

Experimentally, we measured the backside temperature, the chamber temperature, and the heating power which can be used to estimate the equivalent thermal resistance by using $R_{e q}=\left(T_{\text {wall }}-T_{\text {sat }}\right) / V_{P S} I_{P S}$. Our experimental results show that the interfacial resistance has an appreciable contribution to the thermal resistance network. Furthermore, the percentage contribution of the interfacial resistance to the overall thermal resistance depends on the thickness of the thin-film region (i.e., $\left.t_{T F}\right)$. This resistance model was used to predict the temperature difference between the wall and the chamber by multiplying the measured heat flux by portion of the equivalent resistance by using $T_{w a l l}-T_{\text {sat }}=V_{P S} I_{P S}\left(R_{e q}-R_{\text {sub }}\right)$.

\section{Comparison of model and experiments}

Equation (7) predicts that the dryout heat flux scales approximately linearly with the micropillar wick thickness $\left(q^{\prime \prime} \sim H\right)$. To validate this prediction, experiments were carried out on four test devices (devices 2-5, Table 2$)$ with the same $D(\approx 12 \mu \mathrm{m})$ and $L(\approx 20 \mu \mathrm{m})$ but different $H(\approx 35-90 \mu \mathrm{m})$. The heat flux as a function of the temperature difference between the wall and environmental chamber (Fig. 11a) shows that the dryout heat flux increase as $H$ increases from 35 (dashed green line) to $90 \mu \mathrm{m}$ (dashed red line). Increasing the thickness of the micropillar wick increases the flow rate and the dryout heat flux. This 
increasing trend is expected to hold until the micropillar wick thickness becomes comparable to the characteristic length scale of the microstructured surface in which case the Bond number ( $\mathrm{Bo}=\rho_{l} g H^{2} / \sigma_{L V}$ where $g$ is the acceleration due to gravity) becomes greater than 1. As the thickness of the micropillar wick increases, however, the superheat may increase and bubble nucleation may become a concern in terms of limiting the thermal performance, i.e., boiling limit [9]. Both the experimental data and the developed model show that the capillary-limited dryout heat flux scales approximately linearly with micropillar wick thickness (Fig. 11b). The dashed red line in Fig. $11 \mathrm{~b}$ is the model prediction.
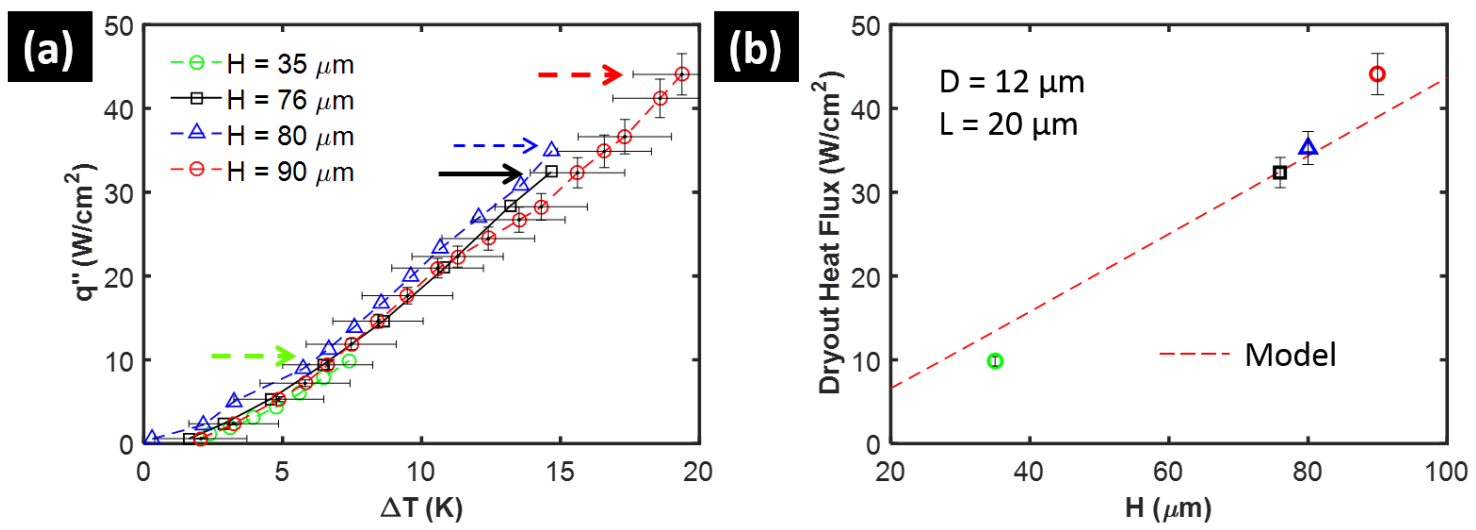

Fig. 11. Effect of micropillar wick thickness on the dryout heat flux. (a) Heat flux as a function of temperature difference between the wall and chamber, i.e., $\Delta T$, and (b) dryout heat flux as a function of micropillar wick thickness. The dryout heat fluxes are shown by the arrows in (a). The dryout heat flux scales approximately linearly with the thickness of the micropillar wick thickness, i.e., $q^{\prime \prime} \sim H$. Increasing the thickness of the micropillar wick enhances the capillary flow and increases the capillary limited dryout heat flux. The superheat, however, may increase as the micropillar wick thickness 
increases and may become the limiting factor for the thermal performance via the boiling limit when the micropillar wick thickness becomes comparable to the dimensions of the microstructured surface.

To investigate the effect of $L$ on the dryout heat flux, three test devices (devices $6,7$, and 8 , Table 2$)$ with similar $D(\approx 8 \mu \mathrm{m})$ and $H(\approx 77-82 \mu \mathrm{m})$ but different $L(12,16$, and $20 \mu \mathrm{m}$ ) were experimentally characterized. For constant $D$ and $H$, when $L$ increases from 12 to $20 \mu \mathrm{m}$, the gain in permeability dominates over the loss in capillary pressure resulting in a net increase in the dryout heat flux (Fig. 12a-b). However, this increase in the dryout heat flux is expected to decrease after reaching an optimum $L(\approx 50 \mu \mathrm{m})$ (Fig. 12b) which maximizes the thermal performance. Beyond this optimum spacing, the loss in capillary pressure exceeds the gain in permeability and the dryout heat flux will decrease. Additionally, the effect of $D$ on the dryout heat flux was characterized experimentally using three test devices (devices 3, 8, and 9, Table 2) with similar $H(\approx 74-77 \mu \mathrm{m})$ and $L(20 \mu \mathrm{m})$ but different $D(5,8$, and $12 \mu \mathrm{m})$. For constant $H$ and $L$, when $D$ increases from 5 to $12 \mu \mathrm{m}$, the loss in permeability dominates over the gain in capillary pressure resulting in a net decrease in the dryout heat flux (Fig. 12c-d). Similarly, an optimum $D(\approx 5 \mu \mathrm{m})$ which maximizes the dryout heat flux exists (Fig. 12d) for a given spacing and micropillar wick thickness. All devices exhibited similar wall temperature, suggesting that the phase change interfacial resistance has an appreciable contribution to the overall thermal resistance. The dashed red lines in Fig. 12b and Fig. 12d are the model predictions. 

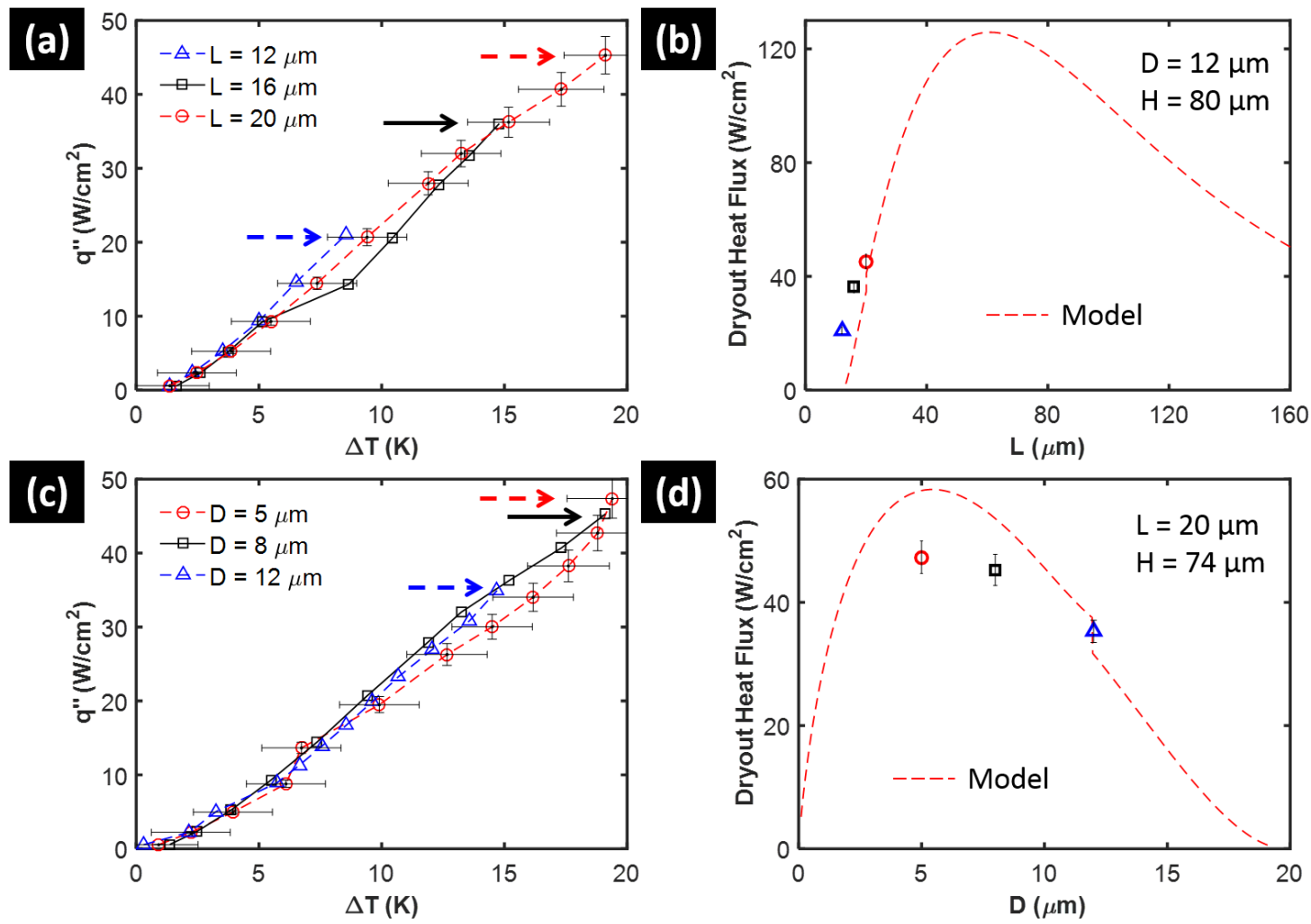

Fig. 12. Effect of spacing (a-b) and diameter (c-d) on the capillary-limited dryout heat flux for a fixed micropillar wick thickness. The dryout heat fluxes are shown by the arrows in (a) and (c). The thermal performance is determined by the competing effects of capillarity and permeability. Our experiments as well as model show that there exists an optimum pillar diameter and spacing that maximizes the dryout heat flux for a given micropillar wick thickness.

All experimental data are plotted against model predictions in Fig. 13. Overall, the experimental data agrees with the model prediction within $\pm 20 \%$ accuracy for both the dryout heat flux (Fig. 13a) as well as the temperature difference between the substrate wall and environmental chamber (Fig. 13b). The temperature difference between wall 
and chamber for the model (abscissa, Fig. 13b) was obtained from the resistance model and the experimentally measured heating power.
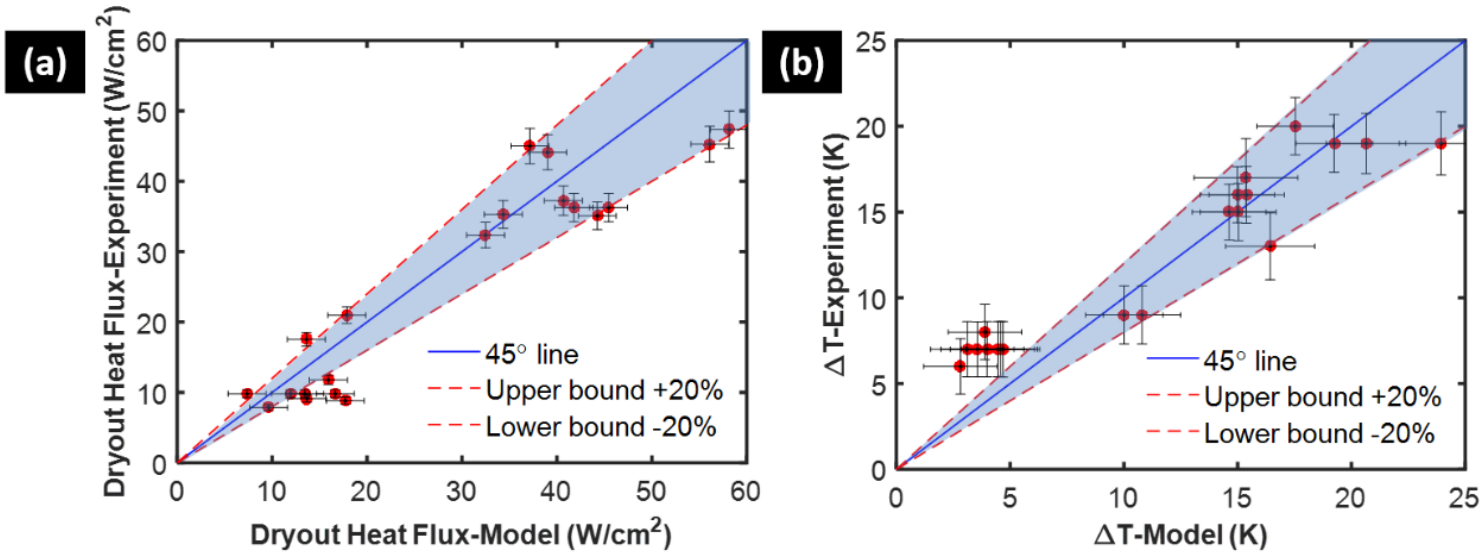

Fig. 13. Model validation for (a) capillary-limited dryout heat flux, and (b) temperature difference between wall and environmental chamber. Our model compares reasonably well ( $\pm 20 \%$ accuracy) with experiments. The error bars on the model dryout heat flux was obtained from the measurement uncertainty in micropillar wick thickness and dryout length via error propagation analysis.

We attribute the discrepancy between model prediction and experimental data to non-isothermal liquid meniscus [37] and non-uniform evaporation. Unlike our assumption, the entire liquid-vapor interface is not at the same temperature and the evaporation rate is not uniform. The liquid-vapor interface near the pillars is at a higher temperature than the liquid-vapor interface at the center of a unit cell [37] causing non-uniform evaporation in a unit cell as well as the entire liquid-vapor interface. The temperature gradient and non-uniform evaporation at the liquid vapor interface may lead to the generation of thermocapillary stresses along the interface [23, 37]. Consequently, 
thermocapillary vortices may form near the liquid-vapor interface due to Marangoni convection $[38,39]$ which is not captured in our model. This may cause improved mixing and increased heat transfer rates. Using micro-particle image velocimetry ( $\mu \mathrm{PIV}$ ) measurements, Dhavaleswarapu et al., [39] visualized the three-dimensional convection patterns near an evaporating meniscus in a capillary tube and observed intense evaporation near the solid-liquid-vapor junction. Marangoni convection in evaporating water under large temperature gradients has been shown to have a significant enhancement on the thermal transport near the liquid-vapor interface [40]. Additionally, the thickness of the liquid varies from the edge (maximum radius of curvature) to the center (minimum radius of curvature) of the microstructured surface. This variation in liquid thickness causes small temperature variations on the top liquid-vapor interface from the edge to the center of the microstructured area for a uniform heat flux. Similarly, our resistance model does not account for this temperature variation. More importantly, our resistance model shows that the contribution of the interfacial resistance to the overall resistance is not insignificant implying that the liquid-vapor interface is at higher temperature than the saturation temperature of the environmental chamber. Despite this appreciable difference in temperature, however, the figure of merit for our model (which is a function of temperature) was evaluated at $24{ }^{\circ} \mathrm{C}$ (saturation temperature of the environmental chamber). We believe that this is one of the contributing factors for the discrepancy between model prediction and experiment. More accurate predictions can be obtained by measuring the evaporating meniscus temperature which is beyond the scope of this study as it requires a different experimental setup and measurement 
tools with high spatial and temporal resolution [41, 42]. Despite these simplifying assumptions, however, the developed semi-analytical model predicts the dryout heat flux and the wall temperature reasonably well within $\pm 20 \%$ accuracy.

\section{Conclusions}

Capillary-limited thin-film evaporation from well-defined silicon micropillar wicks was experimentally characterized. We dissipated $\approx 46 \mathrm{~W} / \mathrm{cm}^{2}$ at $\approx 19^{\circ} \mathrm{C}$ temperature difference between the walls of the micropillar wick and the saturated vapor environment via thinfilm evaporation in the absence of nucleate boiling from a $1 \times 1 \mathrm{~cm}^{2}$ microstructured/heated area. The experimental results are repeatable and independent of flow rate ensuring passive liquid transport via capillary-wicking. When the viscous losses exceed the maximum capillary pressure that can be generated owing to the meniscus shape, the temperature spikes due to liquid starvation, i.e., thermal runaway. Dryout commences at the center of the microstructured area and expands radially outwards altering the heat transfer mechanism from the most efficient two-phase evaporative cooling to the least efficient single-phase natural convective cooling.

We developed a thermal-fluidic semi-analytical model by simultaneously solving the mass, momentum, and energy conservation equations in the evaporating liquid domain. The model prediction for the capillary-limited dryout heat flux agrees with experimental data within $\pm 20 \%$ accuracy. The model and experiment show that the dryout heat flux scales linearly with micropillar wick thickness. Furthermore, both the experiment and model show that there is an optimum pillar diameter and spacing that 
maximizes the dryout heat flux for a given micropillar wick thickness. Lastly, the thermal resistance model shows that the contribution of the interfacial resistance to the overall thermal resistance is appreciable in our devices.

Our model provides mechanistic understanding of the fluidic and thermal transport of thin liquid films evaporation from microstructured surfaces. Two competing parameters (permeability and capillarity) determine the dryout heat flux. Both high permeability as well as high capillarity are required to increase the dryout heat flux. However, high capillarity is obtained from dense pillars while high permeability is obtained from sparse pillars indicating the need for an optimized geometry. The results of this study are applicable to other porous media such as sintered particles and wire meshes. Furthermore, the model can be adopted for other working fluids by changing the thermophysical properties, i.e., the figure of merit. The results of this investigation will assist to better understand the fluidic and thermal transport in micropillar wicks during thin-film evaporation. The insights gained from this study can be used as guidelines to improve the design and optimize the heat transfer performance of wicking structures in heat pipes and vapor chambers, and other high heat flux closed-loop thermal management strategies. 


\section{Acknowledgments}

The authors gratefully acknowledge funding support from Office of Naval Research (ONR) with Mark Spector as program manager and the National Research Foundation Singapore through the Singapore MIT Alliance for Research and Technology's LEES IRG research program. The authors would also like to acknowledge the MIT Microsystems Technology Laboratory for fabrication, staff support and use of equipment. S.A. acknowledges support from the National Science Foundation Graduate Research Fellowship Program (GRFP) under Grant No. 1122374. 


\section{APPENDIX}

\section{A.1 Mathematical derivation}

Assuming 1D heat conduction and uniform evaporation at the liquid-vapor interface, the conservation of energy, mass and momentum equations along with the boundary conditions are given by Eqs. (3)-(6), respectively. The solution of the momentum equation using the appropriate boundary conditions provides the $x$ - and $y$-direction velocity profiles

$$
\begin{aligned}
& u_{x}(x, y, z)=\frac{K}{\mu_{l}} \frac{\partial \mathrm{P}(x, y)}{\partial \mathrm{x}}\left[\frac{e^{H \beta}\left(e^{\beta(H-z)}+e^{\beta(z-H)}\right)}{1+e^{2 H \beta}}-1\right], \\
& u_{y}(x, y, z)=\frac{K}{\mu_{l}} \frac{\partial \mathrm{P}(x, y)}{\partial \mathrm{y}}\left[\frac{e^{H \beta}\left(e^{\beta(H-z)}+e^{\beta(z-H)}\right)}{1+e^{2 H \beta}}-1\right],
\end{aligned}
$$

from which the respective average velocities which depend only on the $x$-and $y$-direction can be obtained by integrating the velocity profile from $z=0$ to $z=H$ as

$$
\begin{aligned}
& \bar{u}_{x}(x, y)=\frac{1}{H} \int_{z=0}^{z=H} u_{x}(x, y, z) d z=\frac{K}{\mu_{l}} \frac{\partial \mathrm{P}(x, y)}{\partial \mathrm{x}}\left(-1+\frac{\tanh (H \beta)}{(H \beta)}\right), \\
& \bar{u}_{y}(x, y)=\frac{1}{H} \int_{z=0}^{z=H} u_{y}(x, y, z) d z=\frac{K}{\mu_{l}} \frac{\partial \mathrm{P}(x, y)}{\partial \mathrm{y}}\left(-1+\frac{\tanh (H \beta)}{(H \beta)}\right) .
\end{aligned}
$$

The $x$ - and $y$-direction average velocities are substituted into the continuity equation to obtain a non-homogeneous second order partial differential equation (PDE) in $x$ and $y$ with pressure as the only variable as 


$$
\begin{gathered}
\frac{\partial^{2} P(x, y)}{\partial x^{2}}+\frac{\partial^{2} P(x, y)}{\partial y^{2}}=-f_{0}, \\
f_{0}=\frac{q^{\prime \prime} \mu_{l}}{H K \rho_{l} h_{f g}\left(-1+\frac{\tanh H \beta}{H \beta}\right)} .
\end{gathered}
$$

The pressure is a function of $x$ and $y$ and four independent boundary conditions are required to solve Eq. (A3). The liquid is supplied from the surrounding water reservoir where the pressure is zero, i.e., the liquid meniscus in the water reservoir surrounding the micropillar wick is flat. Furthermore, the pressure gradient (first derivative of the pressure in $x$ and $y$ ) at the center of the microstructured surface is zero due to symmetry. Consequently, the four boundary conditions are given by

$$
\begin{aligned}
& \left.P(x, y)\right|_{x= \pm l, y}=0, \\
& \left.P(x, y)\right|_{x, y= \pm l}=0, \\
& \left.\frac{\partial P(x, y)}{\partial \mathrm{x}}\right|_{x=0, y}=0, \\
& \left.\frac{\partial P(x, y)}{\partial \mathrm{y}}\right|_{x, y=0}=0 .
\end{aligned}
$$

The non-homogeneous PDE in Eq. (A4) can be transformed into a homogeneous PDE which is easy to solve by redefining the pressure term to make the right hand side of the equation zero. This can be achieved by redefining the pressure as 
International Journal of Heat and Mass Transfer

$$
P(x, y)=\hat{P}(x, y)-\frac{f_{0}}{2}\left(x^{2}-l^{2}\right)
$$

Rewriting Eq. (A3) with the new pressure term transforms the equation to the classical potential (or Laplace) equation as

$$
\frac{\partial^{2} \hat{P}(x, y)}{\partial x^{2}}+\frac{\partial^{2} \hat{P}(x, y)}{\partial y^{2}}=0
$$

Similarly, the boundary conditions stated in Eq. (A4) need to be transformed using the new pressure term to form an equivalent system of equations. The transformed boundary conditions are

$$
\begin{gathered}
\left.\hat{P}(x, y)\right|_{x= \pm l, y}=0, \\
\left.\hat{P}(x, y)\right|_{x, y= \pm l}=\frac{f_{0}}{2}\left(x^{2}-l^{2}\right), \\
\left.\frac{\partial \hat{P}(x, y)}{\partial \mathrm{x}}\right|_{x=0, y}=0 \\
\left.\frac{\partial \hat{P}(x, y)}{\partial \mathrm{y}}\right|_{x, y=0}=0 .
\end{gathered}
$$

The homogeneous PDE in Eq. (A6) can now be solved by splitting it into two linear ordinary differential equations (ODEs) via separation of variables. The general solution is given by 


$$
\hat{P}(x, y)=\sum_{j=1}^{\infty} a_{j} \cosh \left(\lambda_{j} y\right) \cos \left(\lambda_{j} x\right)
$$

where $\lambda_{j}$ is the positive root of the cosine function $\cos \left(\lambda_{j} l\right)=0$ which is given by the infinite series $\lambda_{j}=(2 j-1) \pi / 2 l$ where $j=1,2,3, \ldots$. Substituting the nonhomogeneous boundary condition to the general solution yields

$$
\sum_{j=1}^{\infty} a_{j} \cosh \left(\lambda_{j} l\right) \cos \left(\lambda_{j} x\right)=\frac{f_{0}}{2}\left(x^{2}-l^{2}\right)
$$

Equation (A9) is a Fourier series whose coefficient $a_{j}$ is given by

$$
a_{j}=\frac{f_{0}}{l \cosh \left(\lambda_{j} l\right)} \int_{0}^{l} \cos \left(\lambda_{j} x\right)\left(x^{2}-l^{2}\right) d x=-\frac{f_{0}}{l \cosh \left(\lambda_{j} l\right)} \frac{2}{\lambda_{j}^{3}} \sin \left(\lambda_{j} l\right) .
$$

Substituting the result from Eq. (A10) into Eq. (A8) and substitution for $\hat{P}(x, y)$ from Eq. (A5) yields the actual 2D pressure profile $P(x, y)$ of the evaporating liquid meniscus as

$$
P(x, y)=-f_{0}\left(\frac{2}{l} \sum_{j=1}^{\infty} \frac{\sin \left(\lambda_{j} l\right)}{\lambda_{j}^{3} \cosh \left(\lambda_{j} l\right)} \cosh \left(\lambda_{j} y\right) \cos \left(\lambda_{j} x\right)+\frac{\left(x^{2}-l^{2}\right)}{2}\right) .
$$

Substituting for $f_{0}$ and solving for the heat flux gives 


$$
q^{\prime \prime}=-\frac{H K \frac{\rho_{l} h_{f g}}{\mu_{l}}\left(-1+\frac{\tanh H \beta}{H \beta}\right) P(x, y)}{\frac{2}{l} \sum_{j=1}^{\infty} \frac{\sin \left(\lambda_{j} l\right)}{\lambda_{j}^{3} \cosh \left(\lambda_{j} l\right)} \cosh \left(\lambda_{j} y\right) \cos \left(\lambda_{j} x\right)+\frac{\left(x^{2}-l^{2}\right)}{2}}
$$

The maximum capillary pressure that can be generated from the micropillar wicks is at the center of the microstructured area, i.e., $P(0,0)=-P_{\text {cap }}$. Substituting this value in Eq. (A12) gives the capillary-limited dryout heat flux as

$$
q^{\prime \prime}=-\frac{H K P_{\text {cap }} \frac{\rho_{l} h_{f g}}{\mu_{l}}\left(-1+\frac{\tanh H \beta}{H \beta}\right)}{\frac{l^{2}}{2}-\frac{2}{l} \sum_{j=1}^{\infty} \frac{\sin \left(\lambda_{j} l\right)}{\lambda_{j}^{3} \cosh \left(\lambda_{j} l\right)}} .
$$

To obtain a simplified expression for the dryout heat flux, the infinite series in Eq. (A13) is approximated by using the first term only, i.e., $j=1$. The denominator for $\lambda_{1}=\pi / 2 l$ simplifies to

$$
\frac{l^{2}}{2}-\left.\frac{2}{l} \frac{\sin \left(\lambda_{1} l\right)}{\lambda_{1}{ }^{3} \cosh \left(\lambda_{1} l\right)}\right|_{\lambda_{1}=\pi / 2 l} \approx 0.3 l^{2} .
$$

Substituting this result into Eq. (A13) and rearranging the terms gives the dryout heat flux given in Eq. (7). The constant 10/3 in Eq. (7) comes from this approximation. The final expression for the capillary-limited dryout heat flux shown in Eq. (12) is obtained by substituting for the capillary pressure and replacing the permeability and nominal micropillar wick thickness by the effective permeability and effective micropillar wick thickness, respectively. 


\section{A.2 Interferometry and Surface Evolver simulation}

Interferometry was used to estimate the receding contact angle by capturing the shape of the curved liquid-vapor interface of a receding meniscus. Our experimental setup consisted of a white-light microscope (Eclipse LV-100, Nikon), a laser light source (VT-HAWK, VisiTech International Ltd.), and an EM-CCD camera (ImagEM X2 C9100-23B, Hamamatsu Photonics). The laser source was used to generate a $532 \mathrm{~nm}$ wave length monochromatic light. The diffuse light from the laser source was focused via a 100x microscope objective lens (CFI 60 Infinity Corrected Brightfield Objective, Nikon) with a 0.7 numerical aperture and a $6.5 \mathrm{~mm}$ working distance onto the evaporating curved liquid meniscus. DI water was dispensed onto the microstructured surface via a micro syringe pump with SYS-Micro4 Controller (UMP3, World Precision Instruments). A DC power source (E3632A, Agilent Technologies) was used to heat the $1 \times 1 \mathrm{~cm}^{2}$ microstructured area. The transient evaporation process and the liquid meniscus shape was captured by taking images at 10 frames per second. The images were analyzed to reconstruct the 3D liquid meniscus shape. This was achieved by extracting the in-plane and out-of-plane locations of the dark and bright interference fringes from the images. The vertical distance perpendicular to the receding meniscus (out-of-plane, $z$-direction) between two neighboring fringes (dark and bright pairs) is given by $\omega / 4 n$ where $\omega$ is the wave length of the monochromatic light and $n$ is the index of refraction of water $(n=1.33)$. For a $532 \mathrm{~nm}$ monochromatic light source which was used for this characterization, this out-of-plane height difference between neighboring dark and bright fringes is $100 \mathrm{~nm}$. The in-plane (lateral) location of the fringes was obtained from knowledge of the pillar 
spacing and pixel count. When the liquid starts to recede in a unit cell, the lowest point of the liquid meniscus is the furthest point from the pillars, i.e., the center of the unit cell. The out-of-plane meniscus profile was obtained with respect to this center location. This characterization technique, however, does not capture the steep changes in meniscus shape near the pillar walls. The fringe pattern close to the pillar walls is difficult to resolve due to diffraction. To overcome this shortcoming, we supplemented interferometry with an independent computational technique, i.e., Surface Evolver simulation.

Surface Evolver [31] is a numerical simulation software that minimizes the surface energy of a solid-liquid interaction based on various constraints. One of the input parameters in SE is the contact angle. Based on the input contact angle, surface tension, micropillar array geometry and liquid-solid volume fraction, the SE gives the 3D equilibrium shape of the liquid meniscus that minimizes the thermodynamic energy of the solid-liquid interaction. The meniscus shape in 2D in the diagonal and lateral directions was extracted from the 3D shape obtained from SE via a custom made MATLAB script. These shapes were compared with the data points obtained from interference measurement. The SE simulation is repeated multiple times by systematically changing the contact angle until good agreement between the meniscus shape from SE and the interference data was obtained. The contact angle that gave the least RMSE was chosen as the receding contact angle. 


\section{REFERENCES}

[1] J. R. Thome, "The new frontier in heat transfer: microscale and nanoscale technologies," Heat Transfer Eng., vol. 27, pp. 1-3, 2006.

[2] A. Majumdar, "Thermoelectric devices: helping chips to keep their cool," Nat. nanotechnol., vol. 4, pp. 214-215, 2009.

[3] B. Agostini, et al., "State of the art of high heat flux cooling technologies," Heat Transfer Eng., vol. 28, pp. 258-281, 2007.

[4] I. Mudawar, "Assessment of high-heat-flux thermal management schemes," IEEE Trans. Compon. Pack. Tech., vol. 24, pp. 122-141, 2001.

[5] R. Mahajan, et al., "Cooling a microprocessor chip," in Proc. IEEE, 2006, pp. 14761486.

[6] P.-S. Lee and S. V. Garimella, "Saturated flow boiling heat transfer and pressure drop in silicon microchannel arrays," Int. J. Heat Mass Transfer, vol. 51, pp. 789806, 2008.

[7] B. Deryagin, et al., "To the theory of liquid evaporation from capillaries," Kolloidn. Zh., vol. 26, pp. 301-307, 1964.

[8] V. P. Carey, Liquid-vapor phase-change phenomena: An introduction to the thermophysics of vaporization and condensation processes in heat transfer equipment. New York: Hemisphere, 1992.

[9] G. P. Peterson, An introduction to heat pipes : Modeling, testing, and applications. New York: Wiley, 1994.

[10] P. D. Dunn and D. Reay, Heat pipes, First ed. New York: Pergamon Press, 1976.

[11] D. Ćoso, et al., "Enhanced heat transfer in biporous wicks in the thin liquid film evaporation and boiling regimes," J. Heat Transfer, vol. 134, pp. 101501-11, 2012.

[12] H. Wang, et al., "Characteristics of an evaporating thin film in a microchannel," Int. J. Heat Mass Transfer, vol. 50, pp. 3933-3942, 2007.

[13] Q. Cai and A. Bhunia, "High heat flux phase change on porous carbon nanotube structures," Int. J. Heat Mass Transfer, vol. 55, pp. 5544-5551, 2012.

[14] R. Ranjan, et al., "Wicking and thermal characteristics of micropillared structures for use in passive heat spreaders," Int. J. Heat Mass Transfer, vol. 55, pp. 586-596, 2012.

[15] Y. Wang and G. Peterson, "Analytical model for capillary evaporation limitation in thin porous layers," J. Thermophys. Heat Transfer, vol. 17, pp. 145-149, 2003.

[16] M. Hanlon and H. Ma, "Evaporation heat transfer in sintered porous media," J. Heat Transfer, vol. 125, pp. 644-652, 2003.

[17] C. Li and G. Peterson, "Evaporation/boiling in thin capillary wicks (II)-Effects of volumetric porosity and mesh size," J. Heat Transfer, vol. 128, pp. 1320-1328, 2006.

[18] C. Li, et al., "Evaporation/boiling in thin capillary wicks (I)-Wick thickness effects," J. Heat Transfer, vol. 128, pp. 1312-1319, 2006.

[19] T. Semenic, et al., "Use of biporous wicks to remove high heat fluxes," Appl. Therm. Eng., vol. 28, pp. 278-283, 2008. 
[20] Q. Cai and A. Bhunia, "Characterization of phase change heat and mass transfers in monoporous silicon wick structures," J. Heat Transfer, vol. 136, pp. 072001-8, 2014.

[21] Q. Cai and C.-L. Chen, "Design and test of carbon nanotube biwick structure for high-heat-flux phase change heat transfer," J. Heat Transfer, vol. 132, pp. 0524038, 2010.

[22] J. A. Weibel, et al., "Characterization of evaporation and boiling from sintered powder wicks fed by capillary action," Int. J. Heat Mass Transfer, vol. 53, pp. 42044215, 2010.

[23] R. Ranjan, et al., "Analysis of the wicking and thin-film evaporation characteristics of microstructures," J. Heat Transfer, vol. 131, p. 101001, 2009.

[24] E. W. Lemmon, et al., NIST Standard Reference Database 23: NIST Reference Fluid Thermodynamic and Transport Properties-REFPROP, Version 9.1. Gaithersburg, MD, 2010.

[25] L. U. Manual, "National Instruments," Austin, TX, 1998.

[26] S. G. Rabinovich, Measurement errors and uncertainties: Theory and practice, Third ed. New York: Springer, 2006.

[27] H. Brinkman, "A calculation of the viscous force exerted by a flowing fluid on a dense swarm of particles," Appl. Sci. Res., vol. 1, pp. 27-34, 1949.

[28] A. Sangani and A. Acrivos, "Slow flow past periodic arrays of cylinders with application to heat transfer," Int. J. Multiphase Flow, vol. 8, pp. 193-206, 1982.

[29] C. Byon and S. J. Kim, "The effect of meniscus on the permeability of micro-post arrays," J. Micromech. Microeng., vol. 21, pp. 115011-7, 2011.

[30] F. Renk and P. Wayner, "An evaporating ethanol meniscus-Part I: Experimental studies," J. Heat Transfer, vol. 101, pp. 55-58, 1979.

[31] K. A. Brakke, "The surface evolver," Exp. Math., vol. 1, pp. 141-165, 1992.

[32] D. S. Antao, et al., "Dynamic evolution of the evaporating liquid-vapor interface in micropillar arrays," Langmuir, vol. 32(2), pp. 519-526, 2016.

[33] R. McGlen, et al., Heat pipes: Theory, design and applications, Fifth ed. Burlington: Elsevier, 2006.

[34] X. Xu and V. Carey, "Film evaporation from a micro-grooved surface-An approximate heat transfer model and its comparison with experimental data," J. Thermophys. Heat Transfer, vol. 4, pp. 512-520, 1990.

[35] K. Negus and M. Yovanovich, "Application of the method of optimized images to steady three-dimensional conduction problems," ASME Paper, pp. 9-13, 1984.

[36] R. W. Schrage, A theoretical study of interphase mass transfer. New York: Columbia University Press, 1953.

[37] R. Ranjan, et al., "A microscale model for thin-film evaporation in capillary wick structures," Int. J. Heat Mass Transfer, vol. 54, pp. 169-179, 2011.

[38] L. Scriven and C. Sternling, "The Marangoni effects," Nature, vol. 187, pp. 186188, 1960.

[39] H. K. Dhavaleswarapu, et al., "Experimental investigation of steady buoyantthermocapillary convection near an evaporating meniscus," Phys. Fluids, vol. 19, pp. 082103-11, 2007. 
[40] C. Ward and F. Duan, "Turbulent transition of thermocapillary flow induced by water evaporation," Phys. Rev. E, vol. 69, p. 056308, 2004.

[41] H. K. Dhavaleswarapu, et al., "Microscale temperature measurements near the triple line of an evaporating thin liquid film," J. Heat Transfer, vol. 131, pp. 0615017, 2009.

[42] G. Fang and C. Ward, "Temperature measured close to the interface of an evaporating liquid," Phys. Rev. E, vol. 59, pp. 417-428, 1999. 